University of Nebraska - Lincoln

DigitalCommons@University of Nebraska - Lincoln

2006

\title{
Comprehensive genetic analyses reveal evolutionary distinction of a mouse (Zapus hudsonius preblei) proposed for delisting from the US Endangered Species Act
}

\author{
Tim L. King \\ US Geological Survey, tlking@usgs.gov \\ John F. Switzer \\ US Geological Survey, jswitzer@usgs.gov \\ Cheryl L. Morrison \\ US Geological Survey, cmorrison@usgs.gov \\ Michael S. Eackles \\ US Geological Survey \\ Colleen C. Young \\ US Geological Survey, cyoung@ospr.dfg.cs.gov \\ See next page for additional authors
}

Follow this and additional works at: https://digitalcommons.unl.edu/usgsstaffpub

King, Tim L.; Switzer, John F.; Morrison, Cheryl L.; Eackles, Michael S.; Young, Colleen C.; Lubinski, Barbara A.; and Cryan, Paul, "Comprehensive genetic analyses reveal evolutionary distinction of a mouse (Zapus hudsonius preblei) proposed for delisting from the US Endangered Species Act" (2006). USGS Staff -Published Research. 598.

https://digitalcommons.unl.edu/usgsstaffpub/598

This Article is brought to you for free and open access by the US Geological Survey at DigitalCommons@University of Nebraska - Lincoln. It has been accepted for inclusion in USGS Staff -- Published Research by an authorized administrator of DigitalCommons@University of Nebraska - Lincoln. 


\section{Authors}

Tim L. King, John F. Switzer, Cheryl L. Morrison, Michael S. Eackles, Colleen C. Young, Barbara A. Lubinski, and Paul Cryan

This article is available at DigitalCommons@University of Nebraska - Lincoln: https://digitalcommons.unl.edu/ 


\title{
Comprehensive genetic analyses reveal evolutionary distinction of a mouse (Zapus hudsonius preblei) proposed for delisting from the US Endangered Species Act
}

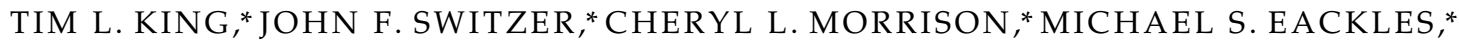 \\ COLLEEN C. YOUNG, BARBARA A. LUBINSKI* and PAUL CRYAN† \\ *US Geological Survey - Biological Resources Division, Leetown Science Center - Aquatic Ecology Branch, 11649 Leetown Rd., \\ Kearneysville, WV 25430, USA, +USGS-BRD, Fort Collins Science Center, 2150 Centre Avenue, Building C, Fort Collins, \\ CO 80526, USA
}

\begin{abstract}
Zapus hudsonius preblei, listed as threatened under the US Endangered Species Act (ESA), is one of 12 recognized subspecies of meadow jumping mice found in North America. Recent morphometric and phylogenetic comparisons among $Z$. h. preblei and neighbouring conspecifics questioned the taxonomic status of selected subspecies, resulting in a proposal to delist the Z. $h$. preblei from the ESA. We present additional analyses of the phylogeographic structure within $Z$. hudsonius that calls into question previously published data (and conclusions) and confirms the original taxonomic designations. A survey of 21 microsatellite DNA loci and 1380 base pairs from two mitochondrial DNA (mtDNA) regions (control region and cytochrome $b$ ) revealed that each $Z$. hudsonius subspecies is genetically distinct. These data do not support the null hypothesis of a homogeneous gene pool among the five subspecies found within the southwestern portion of the species' range. The magnitude of the observed differentiation was considerable and supported by significant findings for nearly every statistical comparison made, regardless of the genome or the taxa under consideration. Structuring of nuclear multilocus genotypes and subspecies-specific mtDNA haplotypes corresponded directly with the disjunct distributions of the subspecies investigated. Given the level of correspondence between the observed genetic population structure and previously proposed taxonomic classification of subspecies (based on the geographic separation and surveys of morphological variation), we conclude that the nominal subspecies surveyed in this study do not warrant synonymy, as has been proposed for Z. h. preblei, Z. h. campestris, and Z. h. intermedius.
\end{abstract}

Keywords: control region, cytochrome b, microsatellite, phylogeography, subspecies, Zapus hudsonius

Received 17 February 2006; revision received 16 June 2006; accepted 28 June 2006

\section{Introduction}

Zapus hudsonius preblei is one of 12 recognized subspecies of meadow jumping mice found throughout North America (Hafner et al. 1981). The distribution of Z. h. preblei is confined to the riparian systems where moisture is most plentiful (Jones et al. 1983). At present, the subspecies' range stretches along the eastern slope of the Rocky Mountains from east-central Wyoming south to Colorado Springs,

Correspondence: Tim L. King, Fax: 304-724-4424;

E-mail: tlking@usgs.gov
Colorado. The availability of suitable riparian habitat is declining throughout the range of Z.h. preblei due to degradation caused by agricultural, residential, and commercial development (US Fish \& Wildlife Service 1998). As a result of diminishing suitable riparian habitat and small population sizes, Z.h. preblei was listed as a threatened species under the US Endangered Species Act (ESA) in 1998 (US Fish and Wildlife Service 1998).

Effective programs for conserving threatened taxa require the identification of unambiguous units of management that reflect evolutionarily important lineages. The issue of defining appropriate units of management becomes acute 
when protection of a taxon under consideration relies on proof of distinction. Subspecies recognition within Z. hudsonius has been based primarily on geographic disjunction and morphological variation (Krutzsch 1954; Hafner et al. 1981) among relatively recently radiated populations. Given that morphological comparisons among accepted species of the genus Zapus have failed to provide reliably diagnostic characters (Jones 1981; but see Conner \& Shenk 2003), it stands to reason that these malleable characters may not prove unfailing at distinguishing intraspecific taxa. Thus, the morphologically similar subspecies of $Z$. hudsonius present significant challenges to conservation biologists because of taxonomic uncertainty (Preble 1899; Krutzsch 1954; Ramey et al. 2005). Taxonomy based solely on morphological characters may not be consistent with phylogenetic relationships, as the rate of evolutionary change can vary among lineages and similar environmental influences may cause convergence (Grant 1987). This can complicate resource management efforts and ultimately jeopardize the ecological and evolutionary potential of a lineage (Moritz \& Hillis 1996).

An integrative conservation approach that identifies and sustains ecological processes and evolutionary lineages is needed to protect and manage the biodiversity present in the southwestern portion of Z. hudsonius' range. Inherent in such an approach is the identification and characterization of associated migration, colonization, and extinction processes among populations of these putative subspecies (Avise 2004). Molecular markers, with a clear heritable genetic basis and the number of characters limited only by genome size (Moritz \& Hillis 1996), provide insight into these processes and can be used to reveal genetic discontinuities and distinctiveness among or between taxa with subtle or undetectable morphological differentiation (Clark et al. 2000). Patterns of gene exchange, the extent of genealogical relationships, and accurate reflections of true evolutionary relationships (i.e. phylogeny) can be revealed through the use of the appropriate type and number of molecular genetic markers (Moritz \& Hillis 1996; Avise 2004).

Recent morphological and genetic comparisons among $Z$.h. preblei and neighbouring con-specifics have questioned the taxonomic status of several subspecies (Ramey et al. 2005, REA). The multidisciplinary study utilized a hypothesis testing approach to determine uniqueness of subspecies, including analyses of cranial morphometrics and contemporary genetic techniques. REA reported that multivariate morphometric analyses on selected cranial measurements failed to support the original description of Z.h. preblei as a distinct subspecies (but see Vignieri et al. 2006). Genetic components of the study compared haplotypes within the mitochondrial DNA (mtDNA) control region and multilocus genotypes at nuclear microsatellite DNA loci. REA concluded that recent gene exchange and low levels of genetic structure among subspecies sup- ported synonymization of Z. h. preblei, Z. h. campestris (Bear Lodge meadow jumping mouse), and Z.h. intermedius (meadow jumping mouse). REA's critical test of uniqueness for Z. h. preblei and related taxa was that greater variance be demonstrated between subspecies than within, a test criterion that, to our knowledge, has not been fully evaluated for taxonomical, biological, or statistical relevance with molecular data. REA constitutes the lone published molecular population genetic analysis of Z. hudsonius, with important implications for the evolution, ecology, and conservation status of $Z$. h. preblei. The proposed synonymy of these subspecies has prompted a subsequent reevaluation of the status of Z.h. preblei under the ESA (US Fish and Wildlife Service 2005).

Studies of phylogeographic relationships among intraspecific taxa often exact a more rigorous study design than that required for interspecific comparisons (Avise 2004). Further, phylogeographic studies can be initially misled by dependence on tissues yielding insufficient quality (Kirchman et al. 2001) and consistency of DNA (Steinberg 1999), inadequate portrayals of genealogical relationships (Brower et al. 1996) through use of inappropriate methodology (Posada \& Crandall 2001), or insufficient resolution from too few molecular or morphological characters (Smouse \& Chevillon 1998). REA utilized dried museum skins from selected collections, assessed the differentiation among selected subspecies of $Z$. hudsonius with a hierarchical pairwise haplotypic distance approach, surveyed sequence variation for a 346 base pair (bp) fragment of the mtDNA control region, and represented nuclear DNA variation with five microsatellite DNA loci. In light of the unproven distinctiveness criteria applied to a relatively small fragment of mtDNA and minimal number of microsatellite loci, the methods applied and conclusions drawn by REA warrant independent verification.

We report additional results concerning the phylogeographic structure and evolutionary distinctiveness of Zapus hudsonius subspecies, placing particular emphasis on the relatedness of $Z$. h. preblei to each neighbouring subspecies by comparing a larger collection of samples over a greater representation of both the mitochondrial and nuclear genomes than was previously investigated. Analyses consisted of evaluating sequence variation at approximately $374 \mathrm{bp}$ of the mtDNA control region and $1006 \mathrm{bp}$ of the mtDNA cytochrome $b$ region, combined with the fragment analysis of a fourfold greater number of nuclear microsatellite DNA loci than surveyed by REA. We tested the null hypothesis that collections of Z. h. preblei, Z. h. campestris, Z.h. intermedius, Z.h. pallidus, and Z.h. luteus comprise a single homogeneous unit (i.e. these subspecies fail to exhibit genetic discreteness) as reflected in the spatial distribution of mtDNA haplotypes and microsatellite DNA allele frequencies. Due to the taxonomic revision proposed by REA, importance was placed on comparisons among 
Table 1 Sample size, allelic richness, number of private alleles, observed and expected heterozygosity, and estimates of $F_{\text {IS }}$ observed for 14 collections of Zapus hudsonius representing five neighbouring subspecies surveyed at 21 microsatellite DNA loci

\begin{tabular}{|c|c|c|c|c|c|c|c|c|c|}
\hline Subspecies & $\begin{array}{l}\text { Collection } \\
\text { abbreviation }\end{array}$ & Collection locality & Cluster* & $\mathrm{N}$ & $A \dagger$ & $\begin{array}{l}\text { Private } \\
\text { alleles }\end{array}$ & $H_{\mathrm{O}}$ & $H_{\mathrm{E}}$ & $\mathrm{F}_{\mathrm{IS}}$ \\
\hline \multirow[t]{10}{*}{ Z.h.preblei } & & & & 170 & 6.7 & [5] & 0.539 & 0.624 & 0.136 \\
\hline & SOWY & Laramie, Albany, Platte, and Converse Counties, WY & & $(28)$ & 4.7 & (1) & 0.499 & 0.553 & 0.099 \\
\hline & LCCO1 & N. Fk. Cache la Poudre River, Larimer County, CO & & $(14)$ & 3.4 & (2) & 0.507 & 0.502 & -0.010 \\
\hline & $\mathrm{LCCO} 2$ & Stove Prairie Creek, Larimer County, CO & Z.h. preblei & $(16)$ & 3.4 & & 0.536 & 0.528 & -0.015 \\
\hline & & & - North & 58 & 5.4 & & 0.511 & 0.614 & 0.169 \\
\hline & DCCO1 & East Plum Creek, Douglas County, CO & & $(34)$ & 4.3 & & 0.538 & 0.535 & -0.005 \\
\hline & $\mathrm{DCCO} 2$ & Indian Creek, Douglas County, CO & & $(30)$ & 4.0 & (1) & 0.538 & 0.540 & 0.004 \\
\hline & ECCO1 & US Air Force Academy, El Paso County, CO & & $(22)$ & 4.4 & (1) & 0.563 & 0.584 & 0.037 \\
\hline & $\mathrm{ECCO} 2$ & Monument Creek, El Paso County, CO & Z.h. preblei & $(26)$ & 4.0 & & 0.586 & 0.559 & -0.050 \\
\hline & & & - South & 112 & 5.7 & & 0.553 & 0.583 & 0.052 \\
\hline \multirow[t]{3}{*}{ Z.h.campestris } & & & Z.h. campestris & 61 & 7.2 & [2] & 0.637 & 0.670 & 0.051 \\
\hline & CCWY & Beaver Creek, Crook County, WY & & $(30)$ & 6.2 & & 0.648 & 0.662 & 0.021 \\
\hline & CCSD & $\begin{array}{l}\text { Iron/Willow Creeks, Custer/ } \\
\text { Pennington Counties, SD }\end{array}$ & & $(31)$ & 6.0 & (1) & 0.625 & 0.654 & 0.045 \\
\hline \multirow[t]{3}{*}{ Z.h. intermedius } & & & Z.h. intermedius & 49 & 9.4 & {$[22]$} & 0.649 & 0.703 & 0.079 \\
\hline & BRCSD & Columbia Road Reservoir, Brown County, SD & & $(28)$ & 6.1 & (8) & 0.619 & 0.637 & 0.029 \\
\hline & MCMN & Camp Ripley, Morrison County, MN & & $(21)$ & 8.3 & (13) & 0.687 & 0.735 & 0.067 \\
\hline \multirow[t]{3}{*}{ Z.h. pallidus } & & & Z.h.pallidus & 48 & 9.4 & {$[33]$} & 0.752 & 0.790 & 0.049 \\
\hline & BCSD & Cedar Creek, Bennett County, SD & & $(16)$ & 6.9 & (9) & 0.738 & 0.757 & 0.026 \\
\hline & KBCNE & $\begin{array}{l}\text { N. Channel Platte River, Kearney/Buffalo } \\
\text { Counties, NE }\end{array}$ & & $(32)$ & 7.5 & (12) & 0.759 & 0.789 & 0.038 \\
\hline Z.h.luteus & SCNM & Multiple sites, Sandoval County, NM & Z.h.luteus & 20 & 4.6 & [8] & 0.576 & 0.623 & 0.076 \\
\hline
\end{tabular}

WY, Wyoming; CO, Colorado; SD, South Dakota; MN, Minnesota; NE, Nebraska; NM, New Mexico.

${ }^{*}$ Clusters $(k=6)$ were determined using the program STRUCTURE.

tAllelic richness.

$\ddagger[]$ indicates the number of private alleles limited to 1 or all collections within a subspecies.

Z.h. preblei, Z.h. campestris, and Z.h. intermedius. In the present study, we accepted as evidence of subspecific distinctiveness the conditions previously defined as significant phylogeographic separation of mtDNA alleles between subspecies (or populations), combined with congruent phylogeographic structure for nuclear loci (Avise \& Ball 1990; Ball \& Avise 1992; Moritz 1994a).

\section{Methods}

Minimally invasive tissue samples (e.g. ear punches and blood) of Zapus hudsonius campestris, Z. h. intermedius, Z. h. pallidus, and $Z$. princeps were obtained from individuals trapped in summer 2005 (Table 1). Archived tissue samples were obtained from Z. h. preblei (ear punch), Z.h. intermedius (frozen liver) and Z.h. luteus (frozen liver) (Appendix A). In order to validate the haplotype data reported by REA as being shared among disjunct and/or highly differentiated subspecies, tissue from 15 specimens was obtained from the University of Kansas Natural History Museum, Lawrence, KS (KUNHM) 11 Z. h. campestris, two $Z$. h. interemedius, and two Z. h. pallidus; Appendix B. These specimens represent seven of the 10 haplotypes reported as being shared among subspecies by REA (haplotypes $\mathrm{C} / \mathrm{P} 1, \mathrm{C} / \mathrm{P} 2, \mathrm{C} / \mathrm{P} 3, \mathrm{C} / \mathrm{P} 4, \mathrm{C}$ /INT-VII, L/PAL/C1, and
$\mathrm{L} / \mathrm{PAL} / \mathrm{C} 2$ ). All tissues were forwarded directly from the collector or museum to the US Geological Survey-Leetown Science Center, Kearneysville, West Virginia for analysis. DNA was obtained from ear punches (in 95\% ethanol), frozen $\left(-80^{\circ} \mathrm{C}\right)$ liver, or blood tissue (on FTA cards; Whatman Inc., Clifton, NJ, USA) and extracted using the PUREGENE DNA extraction kit (Gentra Systems) and resuspended in TE (10 mm Tris-HCl, pH 8.0, 1 mm EDTA). DNA was obtained from dried museum skin sections using the DNeasy Tissue Extraction Kit (QIAGEN) with the manufacturer's protocol modified as described in Iudica et al. (2001).

\section{Microsatellite DNA amplification and fragment analysis}

Twenty-one microsatellite loci developed by three different laboratories were screened in all individuals sampled (Appendix C). The three sets of markers were: (i) Z.7, Z.20, Z.26, Z.48, and Z.52 (REA); (ii) Ztri2, Ztri17, Ztri19, and Ztri24 (isolated from Z. trinotatus; Vignieri 2003); and (iii) ZhuC3, ZhuC6, ZhuC12, ZhuC104, ZhuC119, ZhuC120, ZhuC129, ZhuC130, ZhuD107, ZhuD108, ZhuD109, and ZhuD122 (King et al. 2006). Multiple requests by the US Geological Survey, Leetown Science Center laboratory for tissue or DNA samples to allow standardization with REA 
microsatellite DNA allele scoring were not fulfilled. Microsatellite DNA amplification was conducted under laminar flow and consisted of 100-200 ng of genomic DNA, 1× polymerase chain reaction (PCR) buffer $(10 \mathrm{~mm}$ Tris- $\mathrm{HCl}$, $\mathrm{pH} 8.3,50 \mathrm{~mm} \mathrm{KCl}), 2 \mathrm{~mm} \mathrm{MgCl}{ }_{2}, 0.25 \mathrm{~mm}$ dNTPs, $0.5 \mu \mathrm{M}$ forward (fluorescently labelled) and reverse primer, and $0.1 \mathrm{U}$ Taq DNA polymerase (Promega) in $10 \mu \mathrm{L}$. Amplifications were carried out on either a PTC-200 or PTC-225 thermal cycler (MJ Research) using the following: initial denaturing at $94{ }^{\circ} \mathrm{C}$ for $2 \mathrm{~min}, 35$ cycles of $94{ }^{\circ} \mathrm{C}$ for $40 \mathrm{~s}, 56^{\circ} \mathrm{C}$ for $40 \mathrm{~s}, 72{ }^{\circ} \mathrm{C}$ for $1 \mathrm{~min}$, and a final extension at $72{ }^{\circ} \mathrm{C}$ for $10 \mathrm{~min}$. Fragment analysis was performed on an Applied Biosystems' ABI 3100 Genetic Analyser, as described in King et al. (2001). GENESCAN 2.1 Analysis software and GENOTYPEr 3.6 fragment analysis software (Applied Biosystems) were used to score, bin, and output allelic (and genotypic) data.

\section{Mitochondrial DNA amplification and sequencing}

Two regions of the mtDNA genome were amplified and sequenced. A region of the noncoding control region (CR) was amplified by double-stranded PCR using primers L15926 (5'-TCAAAGCTTACACCAGTCTTGTAAACC-3') and H16498 (5'-CCTGAACTAGGAACCAGATG-3') (Kocher et al. 1989; Shields \& Kocher 1991) for all Z. hudsonius, except the KUNHM specimens used to validate the REA data. The CR sequence of interest could not be amplified for these specimens using the primers LI5320 and ZAP5PLr as described in REA. In order to amplify the CR fragment of interest several internal primers were developed: DLIF1 (5'-TTTACCATTATCCATTCATGCTT-3'), DLIF2 (5'-CAGCACCCAAAGCTGATATT-3'), DLIR1 (5'-TTAAGCCTGACTGAATGTGG-3'). Ultimately a pairing of the primers DLIF1 and H16498 were able to amplify a portion of the CR approximately $366 \mathrm{bp}$ in length. Z. princeps mtDNA $(N=7)$ was amplified using primers L15398 (5'-ATCAGCACCCAAAGCTGATATTC-3') (REA) and H16498. PCRs consisted of an initial denaturation at $94{ }^{\circ} \mathrm{C}$ for $3 \mathrm{~min}$, followed by 35 cycles of $1 \mathrm{~min}$ at $94{ }^{\circ} \mathrm{C}$ (denaturation), $1 \mathrm{~min}$ at $48^{\circ} \mathrm{C}$ (annealing), and $2 \mathrm{~min}$ at $72{ }^{\circ} \mathrm{C}$ (extension), concluding with a final extension period of $5 \mathrm{~min}$ at $72{ }^{\circ} \mathrm{C}$. The KUNHM specimens were amplified using an annealing temperature of $55^{\circ} \mathrm{C}$. The mitochondrial cytochrome $b$ (cyt $b$ ) gene was amplified by double-stranded PCR using two primers designed for this study: L14398A (5'-CCAATGACATGAAAAATCATCG-3') and H15634A (5'-TGGTTTACAAGACCAGAGTAA-3'). PCRs consisted of an initial denaturation at $94{ }^{\circ} \mathrm{C}$ for $3 \mathrm{~min}$, followed by 35 cycles of $1 \mathrm{~min}$ at $94{ }^{\circ} \mathrm{C}$ (denaturation), $1 \mathrm{~min}$ at $55^{\circ} \mathrm{C}$ (annealing), and $2 \mathrm{~min}$ at $72{ }^{\circ} \mathrm{C}$ (extension), concluding with a final extension period of $10 \mathrm{~min}$ at $72^{\circ} \mathrm{C}$. Polymerase chain reactions consisted of $25 \mu \mathrm{L}$ total volume, containing $2.5 \mu \mathrm{L}$ of $\mathrm{MgCl}_{2}$-free buffer, $2.5 \mu \mathrm{L}$ of $\mathrm{MgCl}_{2}$ solution,
$0.5 \mu \mathrm{L}$ of dNTPs (2.5 mm each), $1.25 \mu \mathrm{L}$ of each primer $(10 \mu \mathrm{M}), 1 \mathrm{U}$ Taq polymerase, three $\mu \mathrm{L}$ of template (c. 50$100 \mathrm{ng}$ double-stranded DNA), and $13.75 \mu \mathrm{L}$ of sterile water. Negative controls, which did not include template DNA, were set up alongside PCRs as checks for contamination of PCR reagents. PCR products were purified with exonuclease I and shrimp alkaline phosphatase. The CR and cyt $b$ PCR products were sequenced using ABI BigDye version 3.1 terminator cycle sequencing chemistry, with sequences read by an ABI 3100 Genetic Analyser (Applied Biosystems). The CR fragment was sequenced using primers L15926 or L15398 and H16498 for most specimens. The KUNHM specimens were sequenced using the internal primers DLIF1, DLIF2, DLIR1 and H16498. The cyt $b$ gene was sequenced using primers L14398A and H15634A, and when necessary, internal primers for the cyt $b$ gene. Internal primers designed specifically for this study were: CytbIF1 (5'-CCATTCCATATATTGGCTCA-3'), CytbIF2 (5'-TCCCATTCCATCCTTACTACA-3'), CytbIR1 (5'-CCAATATATGGAATGGCTGA-3') and CytbIR2 (5'-GGGGTATTTAATGGGTTTGC-3'). Cycle sequencing reactions consisted of 30 cycles of $20 \mathrm{~s}$ at $96^{\circ} \mathrm{C}$ (denaturation), $20 \mathrm{~s}$ at $50{ }^{\circ} \mathrm{C}$ (annealing), and $4 \mathrm{~min}$ at $60^{\circ} \mathrm{C}$ (extension). Forward and reverse sequences for each individual were assembled using SEQUENCHER 4.5 (Gene Codes), were aligned to a reference sequence from GenBank (Z. h. preblei, AY598282 for CR and Z. trinotatus, AF119262 for cyt $b$ ), and were double-checked by two researchers. CLUSTAL x (Thompson et al. 1994) was used to obtain multiple sequence alignments for CR and cyt $b$. Alignments of both data sets were performed with default settings and were straightforward as only three sites had indels in the CR data set and no indels were encountered in cyt $b$, as would be expected for this protein-coding gene. Sequences generated in this study are available in GenBank (Accession nos CR DQ664546DQ664900; cyt $b$ DQ664901-DQ665221).

\section{Data analysis}

Microsatellite DNA. Observed genotype frequencies were tested for consistency with Hardy-Weinberg and linkage equilibrium expectations using randomization tests implemented by GENEPOP 3.1 (Raymond \& Rousset 1995). The Hardy-Weinberg test used the Markov chain randomization test of Guo \& Thompson (1992) to estimate exact two-tailed $P$-values for each locus in each sample. Tests for linkage equilibrium were conducted using the randomization method of Raymond \& Rousset (1995) for all pairs of loci. Bonferroni adjustments (Rice 1989) determined statistical significance for these and all other simultaneous tests. Average observed $\left(H_{\mathrm{O}}\right)$ and expected $\left(H_{\mathrm{E}}\right)$ heterozygosities were calculated by BIOsYs-1 (Swofford \& Selander 1981). Amount of allelic diversity (expressed as allelic richness; El Mousadik \& Petit 1996), estimates of population 
subdivision $\left(F_{\mathrm{ST}}\right.$; Weir \& Cockerham 1984), and inbreeding coefficients $\left(F_{\text {IS }}\right)$ were determined using FSTAT (Goudet 1995). All pairwise $F_{\mathrm{ST}}$ estimates between subspecies $(N=5)$ and other intraspecific groupings were tested for significance (i.e. difference from zero) by adjusted permutations using FSTAT. Pairwise $R_{\mathrm{ST}}$ values among subspecies were calculated using GENEPOP 3.1 and are provided for comparison with $F_{\mathrm{ST}}$ values. $F_{\mathrm{ST}}$ assumes allelic diversity results from migration and gene drift, while $R_{\mathrm{ST}}$ also measures mutational differences between alleles. The statistical significance of genetic differences between each pair of collections, clusters, and subspecies was tested using the genic differentiation randomization test in GENEPOP. Results were combined over loci using Fisher's method (Sokal \& Rohlf 1994).

Several techniques were used to describe genetic relationships between subspecies and collections. We used the model-based clustering method of the program STRUCTURE (Pritchard et al. 2000) to infer population structure among collections and probabilistically assign all individuals to detected clusters $(k)$. Due to complex migration patterns assumed to exist among disjunct subspecies, a sequential method of inferring $k$ was used by first identifying the 'uppermost' hierarchical level of population structure followed by subsequent analysis of each cluster to identify within-cluster structure (Evanno et al. 2005). In the initial phase, $k=1$ to $k=15$ clusters were considered for the 14 collections using a burn-in of 15000 followed by 100000 iterations, and 100 independent runs for each $k$. The optimum number of clusters in the initial phase was identified using $\Delta k$ as described by Evanno et al. (2005). Subsequent analysis of each cluster tested $k=1$ to $k=\mathrm{C}+3$ (the number of collections (C) included in the subset plus three), with a burn-in of 10000 followed by 10000 iterations, and 20 runs for each $k$. In the within-cluster analyses, $k$ was also determined using the Evanno et al. (2005) method. Individual assignment success to the cluster or subcluster of origin was recorded as the highest likelihood of assignment $(q)$ and the percentage of individuals in a cluster with $q \geq 0.90$ (Pritchard et al. 2000).

Genetic distances between each pair of collections and subspecies were summarized with $D_{\mathrm{a}}$ (Nei et al. 1983), calculated by DISPAN (Institute of Molecular Evolutionary Genetics, The Pennsylvania State University). Simulation has shown that the geometric-based $D_{\mathrm{a}}$ exhibits a stronger linear relationship over shorter divergence time, and therefore, estimates better tree topology than other commonly used genetic distances when analysing microsatellite DNA variation (Takezaki \& Nei 1996). An unrooted phylogenetic tree was fitted using the $D_{\mathrm{a}}$ distance matrix and neighbourjoining (NJ) algorithm. TreeView (Page 1996) was used to visualize the tree. The strength of support for each node in the tree was tested by bootstrapping over loci using NJBPOP (J.-M. Cornuet, INRA).
Analysis of molecular variance (AMOVA) was used to partition genetic variation among clusters and subspecies (Excoffier et al. 1992). ARLEQUIN 2.0 (Schneider et al. 2000) was used to quantify and test statistical significance of observed differentiation between subspecies, between clusters of collections, and within subspecies and clusters.

Mitochondrial DNA. Unique haplotypes for each data partition (CR, cyt $b$ ) were determined using the program COLLAPSE 1.2 (http://darwin.uvigo.es/software/collapse. html). Sequences of each representative CR haplotype from this study were aligned with the REA data from GenBank and the sequence data from the 15 KUNHM specimens to verify their sequences. CLUSTAL $x$ (Thompson et al. 1994) was used to align the CR data set with default settings as only three sites had indels. Haplotypes were then compared using the program COLLAPSE 1.2 (http:// darwin.uvigo.es/software/collapse.html) to identify matching haplotypes. Sequences from the 15 KUNHM specimens were not used in any subsequent analyses. To examine whether differences in phylogenetic signal existed between the two mitochondrial data partitions, incongruence length differences (ILD, Farris et al. 1994) were calculated in PAUP ${ }^{*}$ by the partition-homogeneity test. Settings for ILD tests were as in parsimony analysis, with uninformative sites excluded, and 1000 replicates per run. The combined data set (cyt $b$ and control region) was examined using maximum parsimony (MP) using PAUP* $4.0 \mathrm{~b} 10$ (Swofford 2002). Parsimony analyses consisted of heuristic searches on unweighted, parsimony-informative (PI) characters with starting trees obtained via stepwise addition, 100 random additions of sequences per run, and tree-bisection-reconnection (TBR) branch swapping on best trees. Nodal support on parsimony trees was assessed using 1000 bootstrap replicates (Felsenstein 1985) with full heuristic searches and Bremer support (Bremer 1988, 1994) using TREEROT version 2 b (Sorenson 1999). Z. princeps was used as the outgroup in all analyses.

Partitioned Bayesian phylogenetic analysis of the combined data set was conducted using the program MRBAYES 3.0 (Huelsenbeck \& Ronquist 2001). The data was partitioned into the control region and first, second, and third codon positions of the cyt $b$ gene. The appropriate model of evolution for each partition was chosen with the Akaike information criterion (AIC) implemented by the program MRMODELTEST. A neighbour-joining tree for the combined data set was generated using the JC model and used for the analysis of each partition with MRMODELTEST. Bayesian phylogenetic analyses were run for $1.0 \times 10^{7}$ generations with random starting trees, default priors, four Markov chains and sampling every 1000 generations. Stationarity of the MCMC analyses was determined by plotting - In L values and individual parameter estimates against generation times. Trees from the burn-in were discarded and the remaining trees used to 


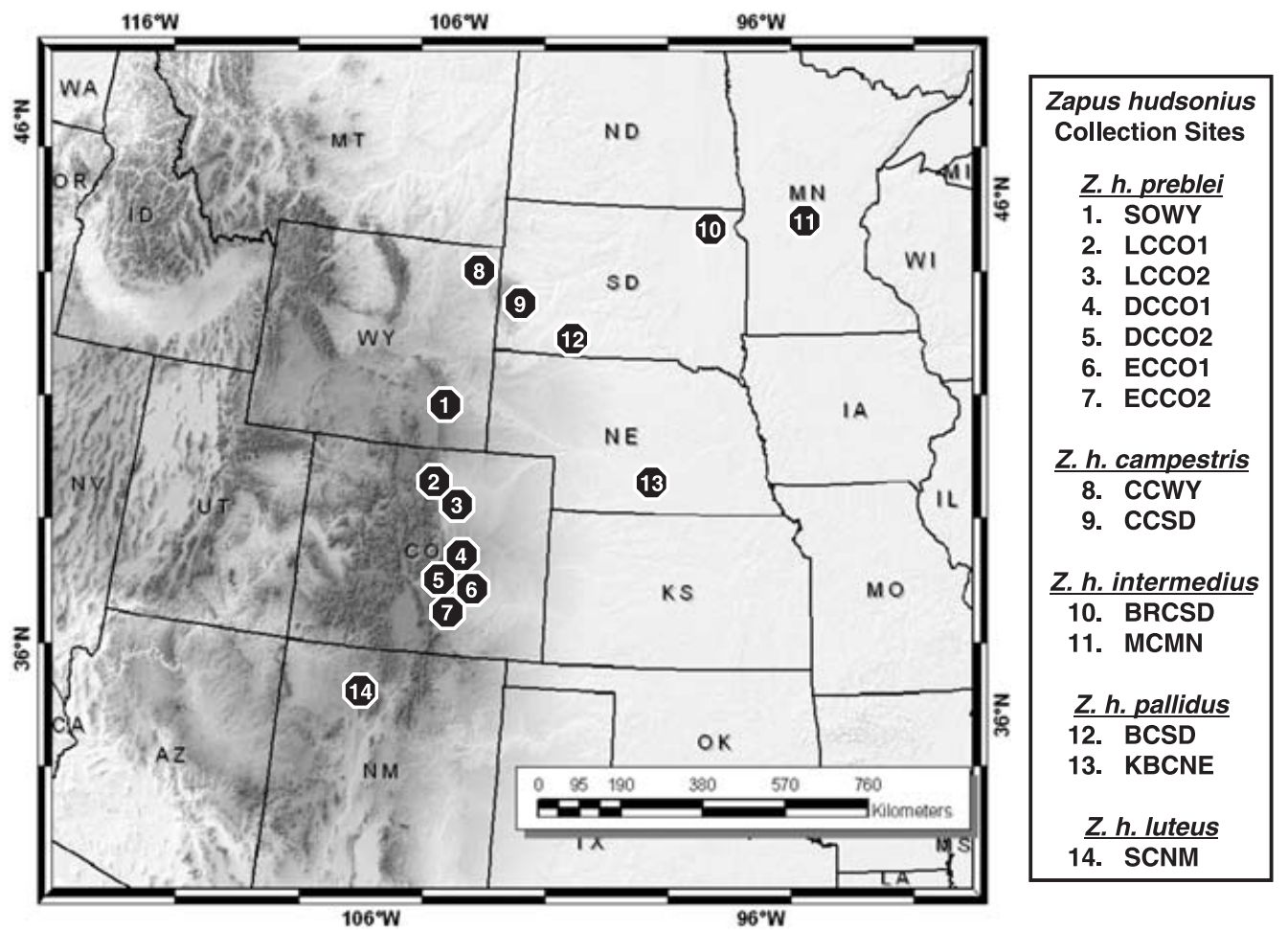

Fig. 1 Generalized collection sites $(N=14)$ representative of five nominal subspecies of Zapus hudsonius utilized in this study. See table 1 for collect site name.

calculate posterior probabilities for clades from their frequencies. Two separate analyses were performed and the resulting topologies and posterior probabilities compared.

We investigated intraspecific gene genealogies for the control region and cyt $b$ data separately using the haplotype networking approach in the TCs computer program (Clement et al. 2000). This analysis implemented the statistical parsimony approach of Templeton et al. (1992) and Crandall et al. (1994).

Nucleotide diversity of the $\mathrm{CR}$, cyt $b$ and combined data sets and exact tests for subspecies and cluster (as defined by STRUCTURE) haplotype differentiation were performed pairwise with 1000 replications in ARLEQUIN 2.0. Total haplotypic variation was partitioned into 'among vs. within' Z. hudsonius subspecies using AMOva. Subspeciesand cluster-level differentiation was assessed using ARLEQUIN 2.0. All AMOVA analyses were conducted in two stages to assess divergence from different evolutionary processes. The first analysis incorporated sequence divergence between haplotypes as well as their frequencies $\left(\Phi_{\mathrm{ST}}\right)$ by calculating either Kimura 2-parameter (CR) or Tamura-Nei (Tamura \& Nei 1993) (cyt $b$ ) estimates. The second analysis, which treated all haplotypes as equally differentiated (i.e. distance $=1.0$ ), assessed the variance distribution based on haplotype frequencies alone $\left(F_{\mathrm{ST}}\right)$. Differences between haplotype frequencies are assumed to be due to genetic drift. The significance of pairwise $\Phi_{\text {ST }}$ and $F_{\mathrm{ST}}$ values were calculated by permuting haplotypes between populations 1000 times.

\section{Results}

\section{Microsatellite DNA}

Genotypes at 21 microsatellite DNA loci were determined for 348 Zapus hudsonius from 14 locations representing five neighbouring subspecies (see Table 1 for listing and abbreviations; Fig. 1). A high level of genetic diversity was detected among the 14 collections; 280 alleles were observed across 21 loci ranging from 7 at $Z h u C 120$ and ZhuC130 to 30 at Z.7 (Appendix C). The mean number of alleles per locus was 13.3. Allelic richness estimates for subspecies ranged from 4.6 (Z.h. luteus) to 9.4 (Z.h. intermedius and Z.h. pallidus) (Table 1). Observed heterozygosity was on average $11.5 \%$ lower in Z. h. preblei than in other subspecies. Observed mean heterozygosity ranged from $53.9 \%$ in Z. h. preblei to $75.2 \%$ in Z. h. pallidus. The number of unique alleles observed ranged from 5 (Z.h. preblei) to 33 (Z.h. pallidus). Estimates of individual pairwise genetic distances, using the proportion of shared alleles, indicated that levels of genetic diversity observed among the 21 microsatellite loci were sufficient to produce unique multilocus genotypes (i.e. genetic distances $>$ zero) for all animals surveyed (distances not presented). 
When organized at the collection level, randomization tests showed that genotypes for the majority of locusby-collection comparisons were consistent with HardyWeinberg expectations. A total of 294 locus-by-collection comparisons were made of which $10(3.4 \%)$ were statistically significant after Bonferroni adjustment for multiple tests at overall $\alpha=0.05(P<0.0036)$. These comparisons consisted of six collections at six loci: CCWY at Z.26; BRCSD and MCMN at ZhuC119; MCMN, BCSD, and KBCNE at ZhuC130; BCSD and KBCNE at Ztri19; MCMN at ZhuC104; and KBCNE at Z.7 (all but the last occurrence due to heterozygote deficiencies). This level of deviation is likely due to one or a combination of factors including substructuring of the sample (i.e. Wahlund effect), inbreeding, or the presence of null alleles. Interestingly, none of the deviations was observed in collections of Z.h. preblei, the subspecies targeted for development of 17 of 21 markers surveyed. This observation, combined with the heterozygote deficiencies observed, suggests that differentiation between $Z$. h. preblei and the neighbouring subspecies may have increased the likelihood that null alleles would be present in the nontarget subspecies. The number of deviations from Hardy-Weinberg expectations increased $(N=26 ; 24.8 \%)$ when collections were pooled as putative subspecies. The majority $(N=15)$ of the significant deviations (overall $\alpha=0.05 ; P<0.01$ ) were observed among the collections pooled as Z.h. preblei. All deviations were the result of heterozygote deficiencies. This result suggests that the allele frequencies of the populations pooled to form this subspecies (Z.h. preblei-North and Z.h. prebleiSouth) have achieved different equilibria and that substructuring (i.e. Wahlund effect) has been detected.

Minimal linkage disequilibrium was observed as five of $2700(0.2 \%)$ comparisons of each locus pair across all collections was found to be significant after correction for multiple tests (overall $\alpha=0.05, P<0.0002$ ). Linkage disequilibrium was observed between Z.20 and ZhuD122, Z.20 and Ztri24,ZhuD107 and ZhuD122, ZhuC12 and ZhuC120, and $Z .48$ and $Z$ tri 2 with the five occurrences distributed among four collections. These findings were likely the result of sampling error, year-class mixing, population mixing, or a combination of the three rather than physical linkage among loci.

Allele frequency heterogeneity was observed throughout the study area. Among 1866 single-locus pairwise tests of allele frequency heterogeneity, $1382(74.1 \%)$ indicated departures from homogeneity after correction for multiple tests $(\alpha=0.05, P<0.0006)$. When testing allele frequency heterogeneity across 21-locus genotypes, highly significant heterogeneity was observed in all 91 pairs of collections $(\alpha=0.05, P<0.001)$.

Results from the STRUCTURE analysis identified that $k=3$ was the appropriate number of clusters to be recognized at the uppermost hierarchical level among the 14 collections of Z. hudsonius genotyped at 21 microsatellite DNA loci.
Ten of the 20 independent runs at $k=3$ resulted in the assignment of the 14 collections to the following clusters: cluster [A] - SOWY, LCCO1, LCCO2, DCCO1, DCCO2, ECCO1, ECCO2 (Z.h. preblei); cluster [B] - CCWY, CCSD (Z. h. campestris) and BRCSD and $\operatorname{MCMN~(Z.h.intermedius);~}$ and cluster $[C]-\mathrm{BCSD}$ and $\mathrm{KBCNE}$ (Z.h. pallidus) and SCNM (Z.h. luteus) (Fig. 2). The other 10 independent runs at $k=3$ resulted in the same clustering with the exception that 27 of $28 \mathrm{Z}$. h. preblei individuals from collection SOWY were assigned to cluster [B], the Z.h. intermedius / Z.h. campestris cluster. An additional 100 independent STRUCTURE runs were conducted at $k=3$, with 57 of the runs assigning all of the SOWY animals to the Z. h. preblei cluster [A]. All of the 57 runs that assigned the SOWY mice to the Z. h. preblei cluster [A] did so with higher average $q$ values (0.93) than the runs that assigned the SOWY animals to the Z.h. intermedius /Z. h. campestris cluster [B] (average $q=0.85$ ). Given the higher number of runs assigning the SOWY collection animals to the Z. h. preblei and the higher assignment values of these runs, this clustering was considered the most appropriate. The three clusters detected as the uppermost hierarchical level of population structure suggest the collections constituting Z.h. preblei form a distinct grouping from the Z.h. campestris and Z.h. intermedius collections, which are also distinct from the $Z . h$. pallidus and Z.h. luteus collections. This structure was confirmed by $100 \%$ correct assignment of each mouse to the cluster-of-origin based on $q$-values (Table 2). The average value of $q \mathrm{MAX}$ for the clusters ranged from 0.96 ([B]) to 0.99 ([C]). Subsequent analysis of the three clusters suggested a strong pattern of genetic differentiation throughout the study area and the presence of $k=6$ definable subclusters (Fig. 2). This analysis identified phylogeographic discontinuities present within Z.h. preblei that corresponded to the northern and southern collections (subclusters 1 and 2, respectively), as well as among clusters allied with Z. h. campestris (subcluster 3), Z. h. intermedius (subcluster 4), Z.h. pallidus (subcluster 5), and Z.h. luteus (subcluster 6). A subsequent analysis of the clusters that assigned SOWY animals to cluster [B] resulted in $k=7$, where the clustering was the same, with the exception being that the SOWY animals were assigned to a unique subcluster. Given these results, we determined that the optimal number of subclusters for these data is six. The strength of the differentiation among these six subclusters was also evident upon inspection of individual assignment results and the average value of $q \mathrm{MAX}$ (Table 2). When each individual was assigned to subcluster based on the largest value of $q$, average assignment success to subcluster of origin was $99.4 \%$ (346 of 348 individuals correctly assigned). Two Z.h. preblei individuals from Z.h. prebleiNorth (subcluster 1 ) were incorrectly assigned to Z. h. preblei-South (subcluster 2). Average values of $q \mathrm{MAX}$ for the six subclusters ranged from 0.94 (Z.h. preblei-North) 
Table 2 Percentage of Zapus hudsonius individuals correctly assigned to one of $k=3$ initial clusters (A-C) and $k=6$ subsequent clusters (subclusters) identified by the program sTRUCTURE from a survey of 14 collections of mice representing five geographically proximal subspecies surveyed at 21 microsatellite loci. Individuals were assigned to cluster or subcluster based on the largest value of $q$. Average $q \mathrm{MAX}$ and percentage of Zapus hudsonius individuals correctly assigned to one of $k=2$ subclusters identified by the program sTRUCTURE based on the $q>0.90$ criterion are also provided

\begin{tabular}{|c|c|c|c|c|c|c|c|c|c|c|c|c|c|c|c|}
\hline \multirow[b]{2}{*}{ Subspecies } & \multirow[b]{2}{*}{ Collection } & \multicolumn{3}{|c|}{ Initial cluster $(k=3)$} & \multirow{2}{*}{$\begin{array}{l}\text { Mean } \\
\text { qMAX }\end{array}$} & \multirow{2}{*}{$\begin{array}{l}\text { Cluster } \\
\text { subcluster } \\
(k=6)\end{array}$} & \multicolumn{2}{|l|}{$[\mathrm{A}]$} & \multicolumn{2}{|l|}{$[\mathrm{B}]$} & \multicolumn{2}{|l|}{$[\mathrm{C}]$} & \multirow{2}{*}{$\begin{array}{l}\text { Subspecies/ } \\
\text { cluster } \\
\text { designation }\end{array}$} & \multirow{2}{*}{$\begin{array}{l}\text { Mean } \\
\text { qMAX }\end{array}$} & \multirow{2}{*}{$\begin{array}{l}\text { Percentage } \\
\text { assigned at } \\
q>0.90\end{array}$} \\
\hline & & {$[\mathrm{A}]$} & {$[\mathrm{B}]$} & {$[\mathrm{C}]$} & & & 1 & 2 & 3 & 4 & 5 & 6 & & & \\
\hline \multirow[t]{9}{*}{ Z.h.preblei } & & & & & & & & & & & & & Z.h.preblei & 0.97 & $100.0 \%(170)$ \\
\hline & SOWY & 1.00 & & & & 1 & 1.00 & & & & & & & & \\
\hline & LCCO1 & 1.00 & & & & 1 & 0.93 & 0.07 & & & & & & & \\
\hline & $\mathrm{LCCO} 2$ & 1.00 & & & & 1 & 0.94 & 0.06 & & & & & North & 0.94 & $89.7 \%(52 / 58)$ \\
\hline & & & & & 0.98 & & & & & & & & & & \\
\hline & DCCO1 & 1.00 & & & & 2 & & 1.00 & & & & & & & \\
\hline & DCCO2 & 1.00 & & & & 2 & & 1.00 & & & & & & & \\
\hline & ECCO1 & 1.00 & & & & 2 & & 1.00 & & & & & & & \\
\hline & $\mathrm{ECCO} 2$ & 1.00 & & & & 2 & & 1.00 & & & & & South & 0.98 & $98.2 \%(110 / 112)$ \\
\hline \multirow[t]{3}{*}{ Z.h. campestris } & & & & & & & & & & & & & Z.h.campestris & 0.98 & $95.1 \%(58 / 61)$ \\
\hline & CCWY & & 1.00 & & & 3 & & & 1.00 & & & & & & \\
\hline & CCSD & & 1.00 & & 0.96 & 3 & & & 1.00 & & & & & & \\
\hline \multirow[t]{3}{*}{ Z. h. intermedius } & & & & & & & & & & & & & Z.h. intermedius & 0.99 & $100.0 \%(49)$ \\
\hline & BRCSD & & 1.00 & & & 4 & & & & 1.00 & & & & & \\
\hline & $\mathrm{MCMN}$ & & 1.00 & & & 4 & & & & 1.00 & & & & & \\
\hline \multirow[t]{4}{*}{ Z.h. pallidus } & & & & & & & & & & & & & & & \\
\hline & & & & & & & & & & & & & Z.h.pallidus & 0.99 & $100.0 \%(48)$ \\
\hline & BCSD & & & 1.00 & & 5 & & & & & 1.00 & & & & \\
\hline & KBCNE & & & 1.00 & 0.99 & 5 & & & & & 1.00 & & & & \\
\hline \multirow[t]{2}{*}{ Z.h.luteus } & & & & & & & & & & & & & Z.h.luteus & 0.99 & $100.0 \%(20)$ \\
\hline & SCNM & & & 1.00 & & 6 & & & & & & 1.00 & & & \\
\hline
\end{tabular}




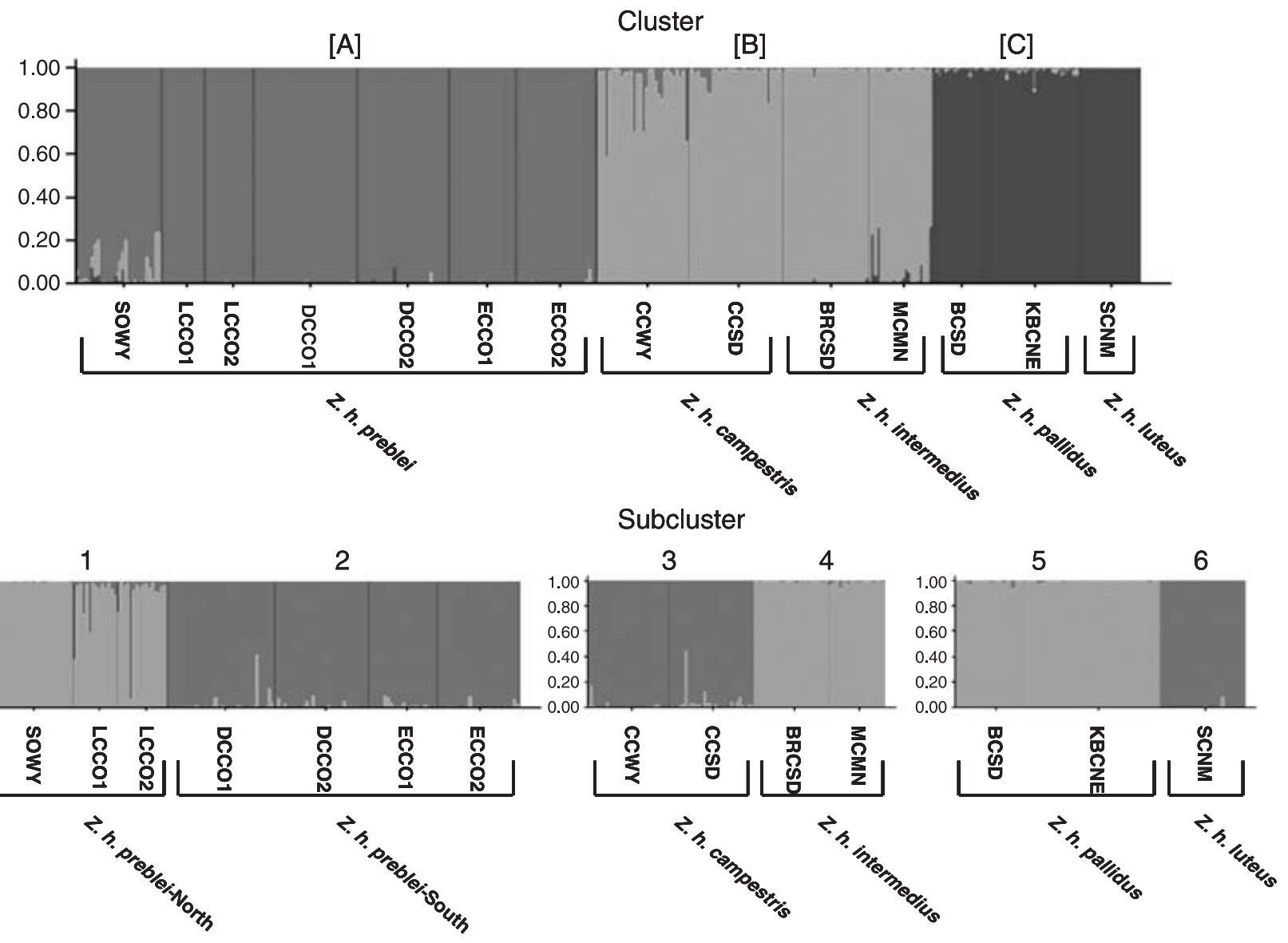

Fig. 2 Summary plots of $q$ estimates generated by the sequential cluster analysis of the program STRUCTURE performed on the multilocus $(N=21)$ genotypes of 14 collections of Zapus hudsonius. The number of inferred clusters $(k)$ in the initial (uppermost hierarchical level) analysis was three (clusters [A-C]). Each initial cluster was subsequently analysed for within-cluster structure. The sequential analysis further subdivided each cluster into two subclusters for a total of six clusters (1-6). Each individual is represented by a single vertical line, broken into $k$ coloured segments, the length of which is proportional to the membership fraction in each of the $k$ clusters. Individuals are grouped by populations and subspecies as indicated by brackets.

to 0.99 (Z.h. intermedius, subcluster 4, Z.h. pallidus, subcluster $5 ; Z$. h. luteus, subcluster 6$)$. When using $q=90$ as an assignment threshold, the percentage of correct assignment to subcluster ranged from $89.7 \%$ (Z.h. preblei-North) to $100.0 \%$ (Z.h. intermedius, Z.h. pallidus, and Z.h. luteus). When compared at the subspecies level ( $q=90$ criterion), assignment success ranged from $95.1 \%$ (Z.h.campestris) to $100 \%$ (Z.h. preblei, Z.h. intermedius, Z.h. pallidus, and Z.h.luteus).

Pairwise genetic distance values $\left(D_{a^{\prime}}\right.$ Nei et al. 1983) were calculated between all collections to investigate evolutionary relationships in allele frequencies. The greatest genetic distances occurred between the Z.h. luteus collection and all other collections; the lowest genetic distances were observed between collections from the same subspecies or cluster (as defined by STRUCTURE). The underlying genetic structure of the $D_{\mathrm{a}}$ matrix is illustrated with an unrooted neighbour-joining (NJ) tree (Fig. 3). The patterns observed illustrate high levels of differentiation among and within the five subspecies and reflects the patterns of genetic variation identified by STRUCTURE. The distinctiveness of the Z. h. preblei collections was confirmed relative to other subspecies by $98 \%$ bootstrap support for separation of the subspecies from all other collections. The SOWY collection from the northernmost portion of the subspecies' range was intermediate between the other northern Z.h. preblei collections and the disjunct (by approximately $150 \mathrm{~km})$ Z. h. campestris collections. In addition, this figure depicts the differentiation observed: (i) among each of the five subspecies; (ii) within each subspecies (excluding $Z . h$. luteus); and (iii) between two major groupings (Z.h. preblei, subclusters 1 and $2 ; Z$. h. campestris, subcluster $3 ; Z$. h. intermedius, subcluster 4 ) and (Z.h. pallidus, subcluster $5 ; Z$. h. luteus, subcluser 6) (100\% bootstrap support). The closest genetic relationship among subspecies exists between Z.h. campestris and Z.h. intermedius. 


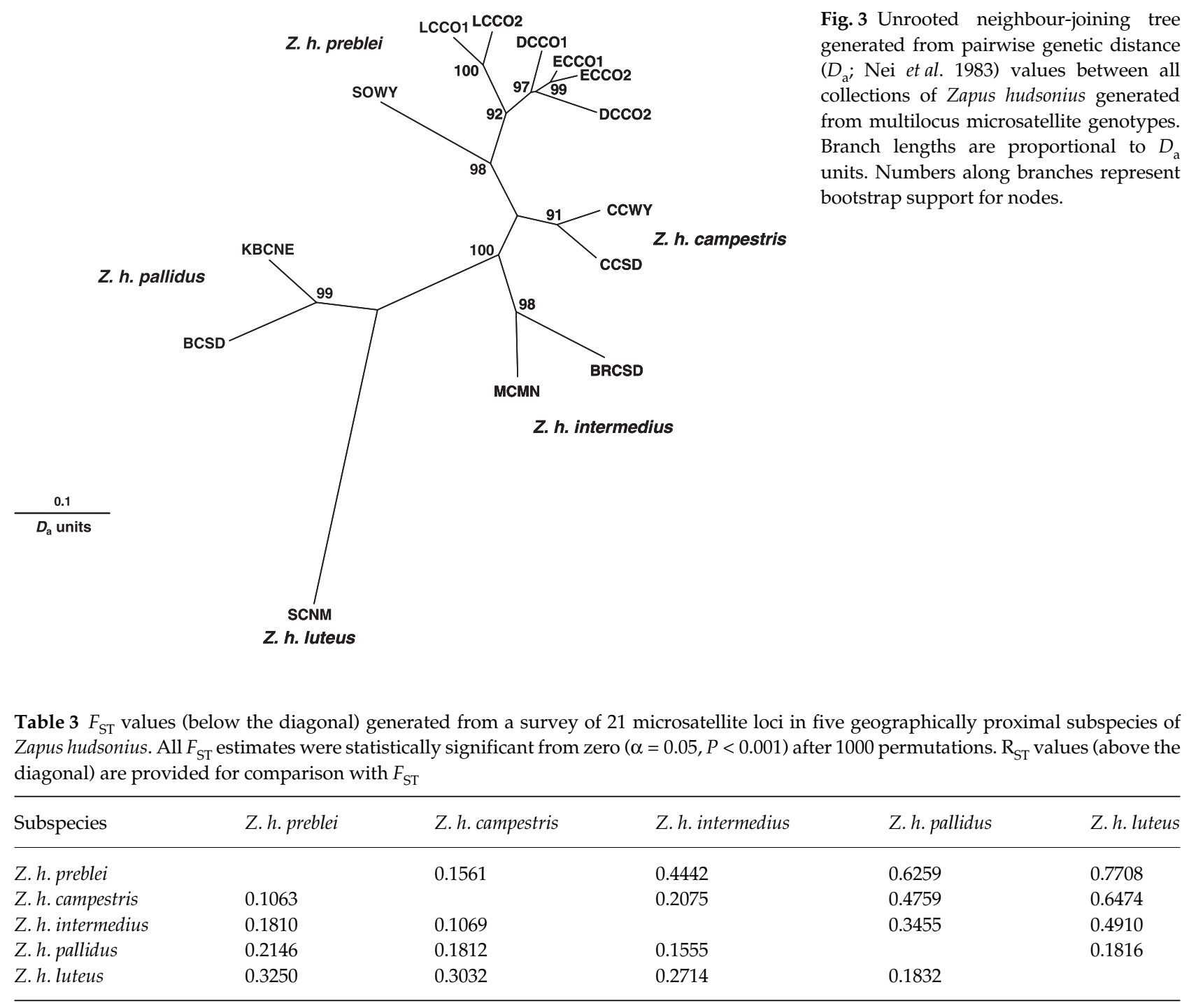

A high level of genetic differentiation was also observed in $F_{\mathrm{ST}}$ comparisons at the subcluster (data not presented) and subspecies (Table 3) scale. All 24 tests of significance in pairwise $F_{\mathrm{ST}}$ values (clusters and subspecies) were statistically greater than zero $(P<0.001)$ indicating numerous significant genetic discontinuities throughout this portion of $Z$. hudsonius' range. The lowest pairwise $F_{\mathrm{ST}}$ value was observed between the two Z.h. preblei subclusters (North and South, 0.10). $F_{\mathrm{ST}}$ estimates were highest between the $Z$.h. luteus subcluster and the Z.h. prebei, Z.h. campestris, and $Z$. $h$. intermedius subclusters (all values $\geq 0.27$ ). Moderately high $F_{\mathrm{ST}}$ estimates were observed between the $Z$.h. preblei and Z.h. campestris subclusters (average 0.12), and between $Z$. $h$. pallidus and the Z.h. intermedius and $Z$. h. campestris subclusters (average 0.15). $F_{\mathrm{ST}}$ estimates at the subspecies level (all collections and subclusters pooled) mirrored those observed among subclusters, with the highest estimates observed between Z.h. preblei and Z.h. luteus, Z. h. campestris and Z.h. luteus, and Z. h. intermedius and $Z$.h. luteus (Table 3). The lowest $F_{\mathrm{ST}}$ estimates were observed among Z.h. preblei, Z.h. campestris, and Z.h. intermedius averaging 0.13 . $R_{\mathrm{ST}}$ values were on average 2.1 times larger than corresponding $F_{\mathrm{ST}}$ values and ranged from 0.16 (Z.h. preblei-Z. h. campestris) to 0.78 (Z.h. preblei-Z.h. luteus) (Table 3). The ratio of $R_{\mathrm{ST}}$ to $F_{\mathrm{ST}}$ values ranged between 1.0 (Z.h. luteus-Z. h. pallidus) and 2.9 (Z.h. preblei-Z.h. pallidus). The observed $R_{\mathrm{ST}}$ values suggest that the differentiation observed among most of the subspecies is considerable as mutational processes have acted to increase differentiation over that observed through random genetic drift.

Quantitative estimates of hierarchical gene diversity (AMOVA) among subspecies and subclusters also identified statistically significant genetic structuring. A comparison between the five subspecies (all collections pooled) determined that $18.4 \%(P<0.001)$ of the genetic variation occurred between subspecies and $81.6 \%(P<0.001)$ was 
due to differentiation within subspecies. Further partitioning resulted in $14.8 \%(P<0.001)$ of the variation being distributed between subspecies, $8.6 \%(P<0.001)$ observed among collections within subspecies, and 76.6\% $(P<0.001)$ of the variance detected within collections. A comparison between the six subclusters (all collections pooled) identified by STRUCTURE yielded results identical to those observed for subspecies partitions $-18.4 \%(P<0.001)$ of the variance due to differences between subclusters and $81.6 \%$ $(P<0.001)$ was attributable to differentiation within subclusters. Partitioning variation among collections within subclusters resulted in slightly more variation being distributed among subclusters (15.4\%, $P<0.001)$, less variation $(6.7 \% ; P<0.001)$ among collections within subclusters, and more variation $(77.9 \% ; P<0.001)$ attributed to variation in collections within subclusters than was observed for subspecies. When subclusters were grouped into subspecies, $11.9 \%(P<0.024)$ of the variation was distributed between subspecies, $7.8 \%(P<0.001)$ was between subclusters within subspecies, and $80.3 \%(P<0.001)$ of the variance was observed within clusters.

\section{Mitochondrial DNA}

Sequence data from Z. hudsonius individuals from 14 collections representing five neighbouring subspecies were analysed for sequence variation at two mitochondrial genes, the 5 '-end of the CR ( $374 \mathrm{bp}, 332$ individuals) and cyt $b$ gene (1006 bp, 320 individuals). In the CR data set 25 haplotypes were recovered with $28(7.5 \%)$ sites variable, $27(7.2 \%)$ sites parsimony-informative, and three indels parsimony-informative when coded as a fifth base (Appendix D). For the cyt $b$ region, 56 haplotypes were recovered with $116(11.5 \%)$ sites variable, $84(8.3 \%)$ sites parsimonyinformative and no indels present (Appendix E).

Control region sequences were obtained for 15 of the KUNHM specimens utilized by REA. When these sequences were compared to the REA data from GenBank and representative CR haplotypes from this study, 13 of the sequences were different than those reported by REA (Table B.1, Appendix B). All seven of the Z.h. campestris that were reported as having Z.h. preblei haplotypes by REA were found to have common Z.h. campestris haplotypes. Given these results, the validity of all the REA data from the mitochondrial DNA genome is called into question, and therefore was not combined with the data from this study for any analyses.

Adjusted (net) mtDNA sequence divergence estimates (Kimura 2-parameter, CR and Tamura-Nei, cyt $b$ ) between $Z$. hudsonius subspecies were relatively low, averaging $3.37 \%$ (CR) and $4.43 \%$ cyt $b$ (not shown). Net distances between $Z$. hudsonius subspecies ranged between $0.29 \%$ (CR) and $0.18 \%$ (cyt $b$ ) for the most closely related subspecies, Z.h. campestris and Z.h. intermedius, to $5.63 \%$
(Z.h.campestris-Z.h.luteus, CR) and $7.11 \%$ (Z.h. campestris$Z$.h. pallidus, cyt $b)$. Z.h. preblei was least divergent from Z.h. intermedius $(0.57 \%, \mathrm{CR}$ and $0.68 \%$, cyt $b)$, and most divergent from Z. h. luteus $(5.08 \%, \mathrm{CR})$ or Z. h. pallidus $(6.76 \%$, cyt $b$ ). Divergence estimated from CR between Z. h. preblei and Z. h. campestris (1.03\%) was nearly twice that observed between Z. h. preblei and Z.h. intermedius. Estimates of divergence between $Z$. hudsonius subspecies and Z. princeps, used as an outgroup in phylogenetic analyses, were higher $(10.33 \%$, CR and $19.87 \%$, cyt $b)$.

Nucleotide diversity within subspecies was low across the study, and ranged from 0.0000 in Z. h. luteus (both gene regions) to 0.0060 and 0.0030 in Z. h. pallidus (Table 4, CR and cyt $b$, respectively). Twenty-five (CR) and 56 (cyt $b$ ) haplotypes were observed study-wide for Z. hudsonius, yet none were shared among the five subspecies (Appendices B and C). For Z. h. preblei, 1 of 4 CR haplotypes and none of the 21 cyt $b$ haplotypes were shared between the northern and southern clusters.

Statistical parsimony analyses of sequence data from each mitochondrial gene region produced largely concordant haplotype networks. In the CR analysis with gaps included as a fifth character state, the 0.95 limit for connections was eight steps and in the cyt $b$ data set the 0.95 limit was 13 steps. Both analyses produced multiple networks, but both included a single network including all Z. h. preblei, Z.h. intermedius, and Z.h. campestris haplotypes. In the CR analysis, a second network was formed by Z.h. pallidus and Z. h. luteus haplotypes (figure not shown), where these haplotypes formed two separate networks corresponding to subspecies based on cyt $b$ (Fig. 4). Within the (Z. h. prebleiintermedius-campestris) networks, haplotypes made up of individuals from each subspecies clustered together (subspecies outlined in boxes) and were separated from other subspecies' haplotypes by one (CR) to six (cyt $b$, prebleiintermedius, Fig. 4) mutational steps. The same three Z.h. intermedius individuals had CR (ZhiCR_E) and cyt $b$ (ZhiCB_A, Fig. 4) haplotypes that had fewer mutational steps to a Z. h. campestris haplotype than to other Z. h. intermedius haplotypes; yet these haplotypes were not found in any $Z$. h. campestris individuals $(N=61)$.

Analysis of molecular variance (AMOvA) of data from each mitochondrial gene region indicated the presence of strong, significant genetic differentiation among the five Z. hudsonius subspecies surveyed. Global $\Phi_{\mathrm{ST}}(0.89$ for CR and 0.96 for cyt $b$ ) and $F_{\mathrm{ST}}$ ( 0.36 for CR and 0.29 for cyt $b$; not shown) values were high and significantly different from zero $(P<0.00001)$. As no haplotypes were shared among the five $Z$. hudsonius subspecies, $F_{\mathrm{ST}}$ values (a measure of haplotype frequencies only) generated by the AMOvA analysis have limited biological resolution and are discussed only for comparison to previous findings (REA). A global $\Phi_{\mathrm{ST}}$ of 0.96 indicates that nearly all of the haplotype variance $(96 \%)$ was distributed between subspecies, a result 


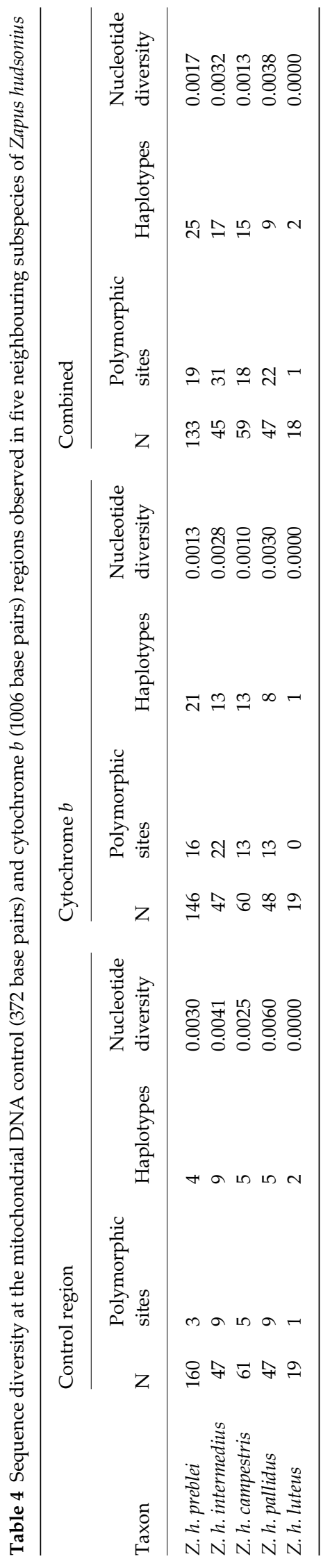

consistent with the absence of any shared haplotypes observed between subspecies. In general, comparisons among all subspecies resulted in higher $\Phi_{\mathrm{ST}}$ values for cyt $b$ than for CR but with one exception, the comparison between Z.h. intermedius and Z.h. campestris, which also were the lowest $\Phi_{\mathrm{ST}}$ estimates ( $\mathrm{CR}=0.59$, cyt $\left.b=0.53\right)$. A comparison of haplotype variation among the three subspecies proposed for synonymy by REA, Z. h. preblei, Z. $h$. intermedius and Z.h. campestris, resulted in $73 \%(\mathrm{CR})$ and $83 \%$ (cyt $b$ ) of the variance being distributed among subspecies. Moreover, AMOVA results suggest that Z. h. preblei is distinct from other neighbouring subspecies and is evolutionarily more similar to $Z$. $h$. intermedius than to $Z$. $h$. campestris, as $\Phi_{\mathrm{ST}}$ estimates were lowest with $Z$. h. intermedius $\left(\Phi_{\mathrm{ST}}=0.67, \mathrm{CR}\right.$ and $\Phi_{\mathrm{ST}}=0.82$, cyt $\left.b\right)$ and slightly higher when compared with Z. h. campestris $\left(\Phi_{\mathrm{ST}}=0.79, \mathrm{CR}\right.$ and $\Phi_{\mathrm{ST}}=0.89$, cyt $b$ ). This finding differs from the pattern observed during analysis of the nuclear DNA, which found Z.h. preblei to exhibit a lower genetic distance between Z.h. campestris than Z.h. intermedius. All estimates of subspecies from different mitochondrial clades (Fig. 5A) were above 90\%, with both Z.h. preblei and Z.h. campestris reaching $98 \%$ in comparisons with $Z$. h. luteus. Haplotype variation distributed among the clusters indicated by the nuclear microsatellite loci by the program STRUCTURE was similar to that observed among the subspecies, as $90.0 \%$ of the $C R$ variation and $95.4 \%$ of the cyt $b$ variation $(P<0.001)$ was attributable to differentiation among subclusters and the remainder due to variation within. These findings mirrored the high level of genetic differentiation observed upon survey of these subclusters with the nuclear microsatellite DNA markers. Exact tests for differentiation based on haplotype frequencies for both gene regions and clusters ( $N=15$ comparisons) were statistically significant $(P<0.001)$.

\section{Combined mitochondrial DNA}

Results of ILD tests were not significant $(P=0.23)$, plus phylogenetic analyses of the individual data partitions were congruent with respect to the major clades recovered (data not shown); so data was combined for individuals occurring in both data sets (303 individuals), then collapsed into 69 unique haplotypes (68 Zapus hudsonius, 1 Z. princeps Table 4). The strict consensus tree of 8032 most parsimonious trees (Fig. 5a) revealed two well-supported clades within Z. hudsonius. One clade, supported by $100 \%$ of bootstrap pseudoreplicates and a decay index of 17 , was comprised of Z. h. pallidus and Z. h. luteus haplotypes, and the two Z. h. luteus haplotypes formed a well-supported monophyletic group. The other major clade recovered was comprised of Z. h. intermedius, Z. h. campestris, and Z. h. preblei haplotypes (bootstrap $=100$, decay index 36, Fig. 5a). Within this clade, none of the $Z$. hudsonius subspecies were recovered as 


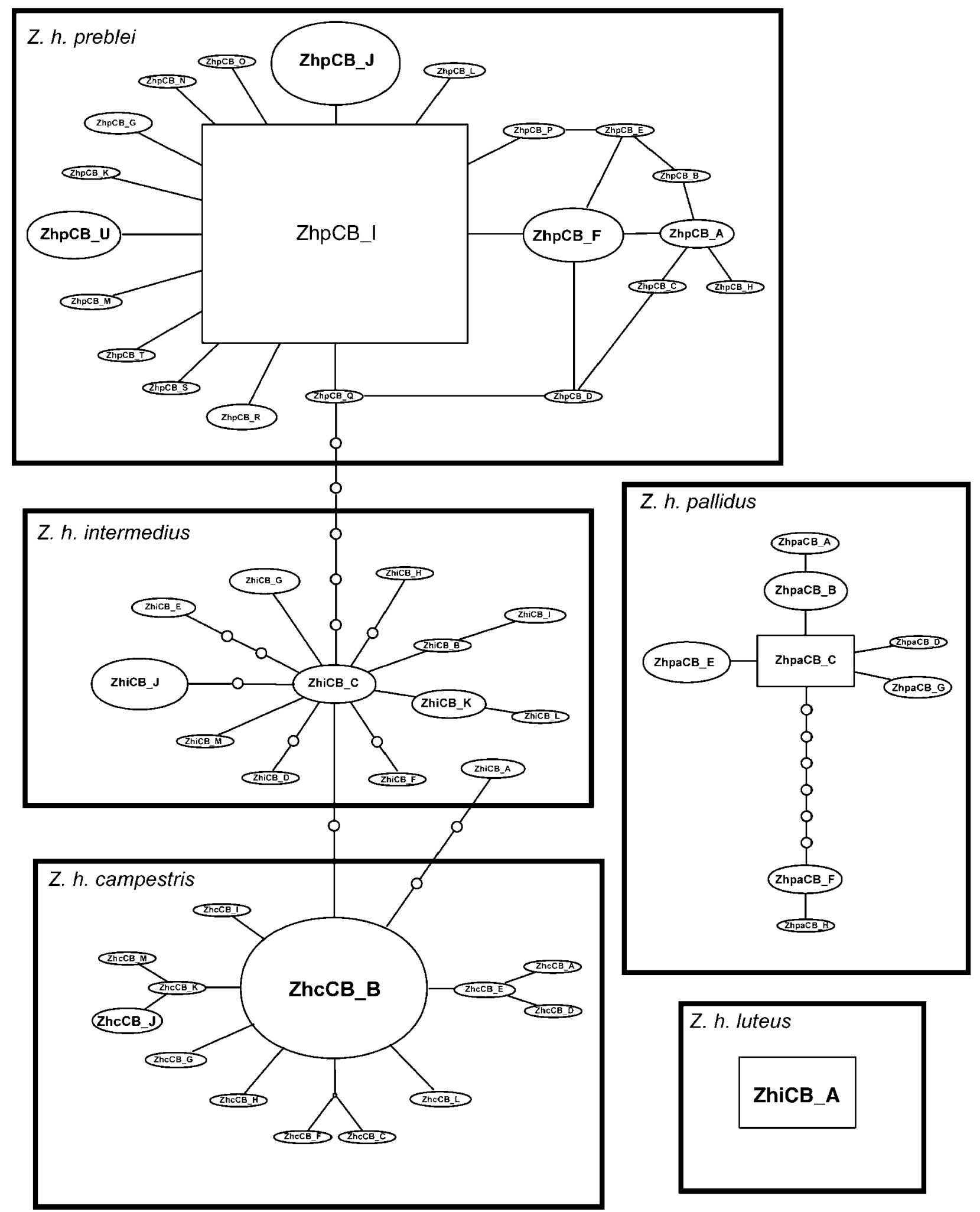

Fig. 4 Zapus hudsonius haplotype networks resulting from the statistical parsimony analysis of the cyt $b$ data set. The set of haplotypes belonging to each subspecies of Z. hudsonius are outlined by boxes. No haplotypes were shared among subspecies. Haplotypes identified as the root of each network by the program TCs (Clement et al. 2000) are represented by a square and all other haplotypes are represented as circles. The size of each haplotype symbol is proportional to the number of copies observed in the data set. Haplotypes for Z. h. pallidus and Z.h. luteus are not connected to the network containing Z. h. preblei due to the differentiation exceeding the $95 \%$ limit for connections for cyt $b$ (13\%). 
4344 T. L. KING ET AL.

A

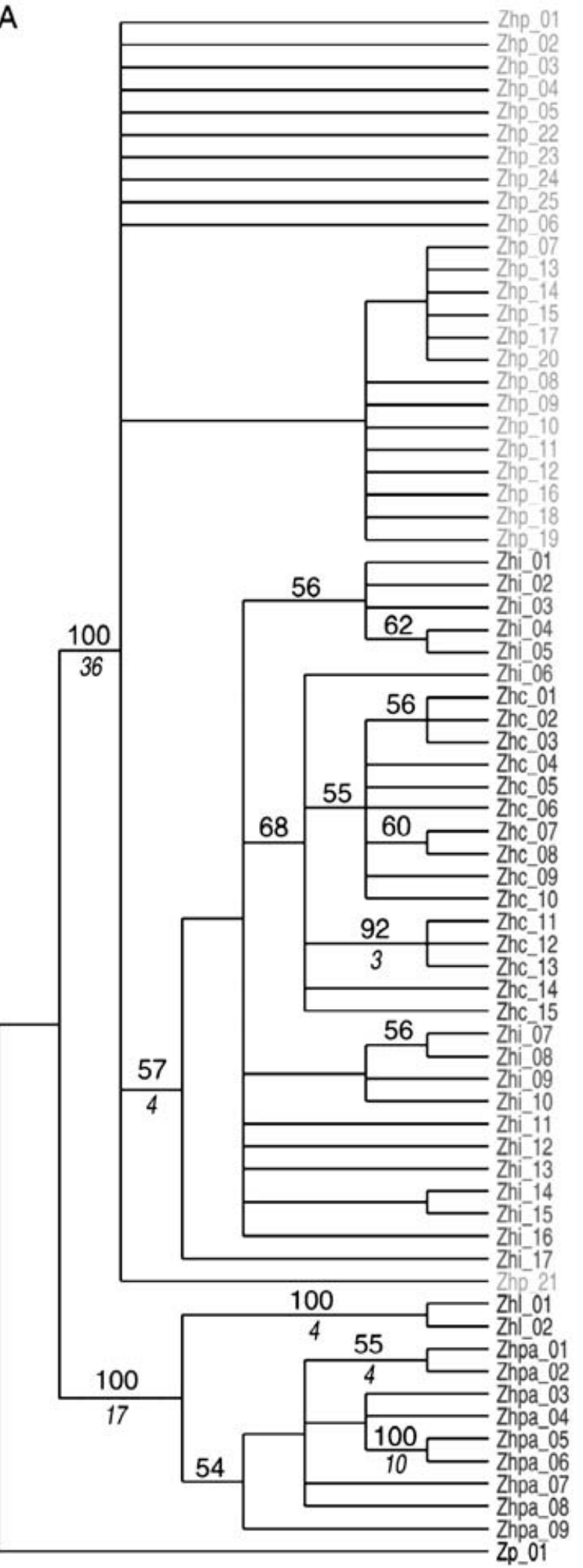

B

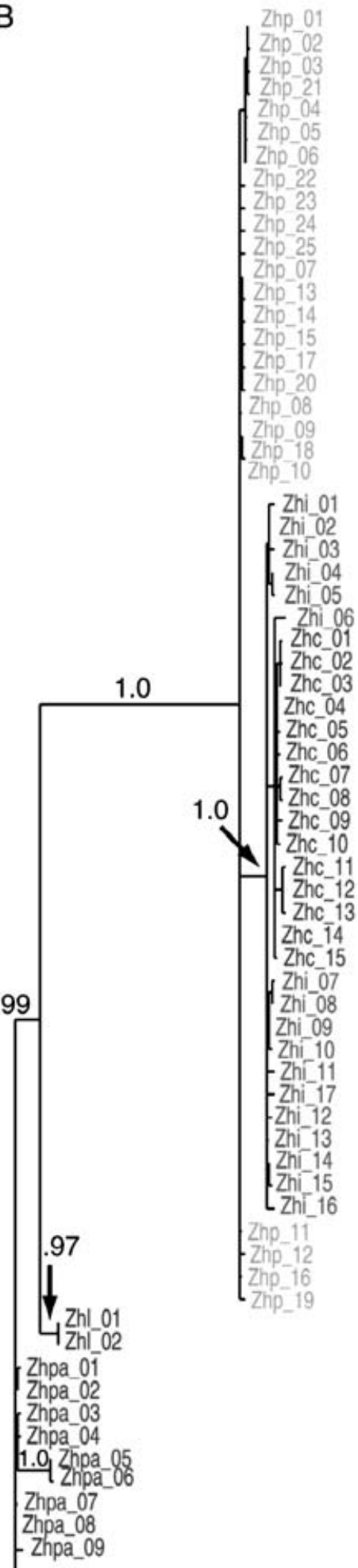

Zhpä_09

\section{- 5 changes}

Fig. 5 Phylogenetic hypotheses for five Zapus hudsonius subspecies based upon combined mitochondrial DNA data: (A) strict consensus of 8032 most parsimonious trees (359 steps, $\mathrm{CI}=0.8273$ ) and $(\mathrm{B})$ phylogram resulting from partitioned Bayesian analysis. Numbers above branches in A are bootstrap proportions and italicized numbers below branches in A are decay indices, numbers above branches in $\mathrm{B}$ are posterior probabilities of nodes. 
monophyletic, yet the Z.h. campestris/intermedius haplotypes formed a clade paraphyletic to Z.h. preblei haplotypes (bootstrap values of 57, decay index of 4, Fig. 5a). Generally, nodes within this major clade were poorly supported by bootstrap and decay indices.

Models select using the AIC by MRMODELTEST for the control region and first, second, and third codon positions of the cyt $b$ gene were HKY+I+G, K80+I, GTR+I, and GTR respectively. In all Bayesian analyses stationarity was reached by 50000 generations, therefore the first 50 trees were discarded as burn-in and the remaining trees used to calculate topology and posterior probabilities. Topologies of the consensus trees from the two Bayesian analyses were identical and posterior probabilities for each clade varied by no more than 0.01 (Fig. 5b, one of two Bayesian consensus trees). The trees resulting from the Bayesian analysis were similar in topology to the MP consensus (Fig. 5a), with the major difference being the relationship between Z. h. pallidus and Z. h. luteus - they are not sister taxa in the Bayesian analysis (Fig. 5b). In the phylogram of the Bayesian tree (Fig. 5b), it is notable that branch lengths were short within the Z.h. campestris/intermedius/preblei clade, with the longest branch (and the only one with a significant posterior probability) separating Z.h. preblei from Z.h. campestris/intermedius haplotypes.

\section{Discussion}

The disjunct collections represented in the present study may not qualify as distinct species because their reproductive barrier is extrinsic, but their apparently long-standing separation has resulted in the accretion of considerable genetic differentiation that is reflected in geographically congruent patterns of divergence at multiple DNA markers. The magnitude of the observed differentiation was considerable and supported by highly significant findings for nearly every statistical comparison, regardless of the genome or the taxa under consideration. Given the strong structuring of nuclear multilocus genotypes, the presence of only subspecies-specific mtDNA haplotypes, and that the genetic discontinuities correspond with previously proposed taxonomic classifications based on geographic separation and morphological variation among these Zapus hudsonius subspecies (Krutzsch 1954; Hafner et al. 1981), we find no genetic evidence warranting taxonomic revision among the Z.h. preblei, Z.h. campestris, and Z.h. intermedius as previously proposed (REA), nor suggesting the need to alter Z.h. preblei's standing under the ESA. Moreover, the level of differentiation observed between Z.h. preblei inhabiting southern Wyoming and Larimer County, CO (Z.h. preblei-North) and mice sampled from Douglas and El Paso counties, CO (Z.h. preblei-South) indicates that this subspecies is comprised of at least two genetically distinct populations worthy of individual management consideration. Spatial genetic structuring apparent in Z. hudsonius subspecies is reminiscent of that observed in Zapus trinotatus (Pacific jumping mouse). Through a landscape genetics approach, Vignieri (2005) explored the interactions between dispersal and environmental characteristics and found that both restricted dispersal and habitat-directed movement were likely forces shaping fine-scale genetic patterns between populations. Sufficient data have also been presented to suggest that the differentiation observed between the Z.h.pallidus and Z. $h$. luteus clade and other $Z$. hudsonius subspecies warrants further study and serious consideration given to specieslevel recognition for the former.

The findings of this study are contradictory in nearly every comparison with the conclusions drawn from the only other molecular genetics data available on the taxonomic status of $Z$. hudsonius subspecies (REA). It is imperative that the disparities between the previous and present study be discussed due to the conservation implications of synonymizing Z.h. preblei, Z.h. campestris, and Z.h. intermedius as proposed by REA, and the misleading precedent that may be accepted for evaluating the genetic basis for listing under the ESA unless these discrepancies are understood by scientists and properly portrayed to resource managers. The largest differences between the two studies dealt with the presence or absence of haplotype sharing among subspecies and the philosophical perspective with which the researchers interpreted the findings (see Conservation implications). It was particularly troubling that the CR sequences of 13 specimens reported by REA to possess shared haplotypes between subspecies were not substantiated when sequenced for this study (see Appendix B). Equally troubling was that 80 of the 222 total sequences deposited to GenBank by REA cannot be directly linked to the specimens listed in Appendix 2 of REA because accession numbers are not provided and the isolate names listed on GenBank for the 80 sequences do not match ID numbers given in REA. The inability to directly link the sequences deposited in GenBank to the specimens listed in REA and the associated locality data renders the data useless. Possible reasons for the different sequences reported by REA are contamination, mislabelling of samples, or other procedural incongruity. Given that all the specimens re-evaluated in the current study were found by REA to have haplotypes that were shared among subspecies, the disagreement in DNA sequences reported for these individuals calls into question all of the results of REA based on the mitochondrial DNA genome and prevents meaningful analysis of the combined data. Moreover, this study and that of REA differ in sampling regime, number of molecular characters sequenced and microsatellite fragments surveyed, test statistics applied to AMOvAs, methods used to portray genealogical relationships, and criteria used to determine uniqueness. We will discuss the nature of these 
discrepancies and suggest how each approach impacts the conclusions drawn regarding subspecies distinctness.

An appropriate sampling strategy is central to the successful delineation of population genetic and phylogeographic structures (Baverstock \& Moritz 1996). The 'population-oriented' strategy used in the present study differed significantly from the 'one or few individuals per site across a broad geographical area' approach applied by REA. This study focused on collections ranging from 14 to 33 individuals from recognized geographic populations, increasing the likelihood that the majority of haplotypes within a population would be surveyed. Total genetic variation within $\mathrm{Z}$. hudsonius can be hierarchically partitioned: (i) between subspecies, (ii) among populations within subspecies, and (iii) within populations. The sampling strategy and subsequent analyses performed by REA likely underestimated the level of within-population variation, effectively inflating within-subspecies variance, while potentially lowering the total variance attributed to between-subspecies differentiation. This sampling strategy may have decreased the likelihood that distinctiveness (as defined by REA) would be demonstrated. While both sampling strategies have their strengths and weaknesses and a combination of the two may ultimately be preferred, we believe the strategy used in the present study is the more pragmatic approach for testing statistical significance under the hypothesis testing approach espoused by REA, in which uniqueness was based on partitioning of variation within and between subspecies. The systemic error identified in the REA CR region sequences prevented an analysis of the combined data.

Large numbers of microsatellite DNA loci provide better estimates of population genetic parameters given the stochastic variation (including size homoplasy) expected among independent loci (Takezaki \& Nei 1996; Adams et al. 2004). Given that microsatellite loci are densely interspersed in eukaryotic genomes (Katti et al. 2001), five polymorphic microsatellite DNA loci may not provide sufficient representation of the nuclear DNA variation present (Beaumont \& Nichols 1996; Pritchard \& Rosenberg 1999) or provide a sufficiently robust multilocus genotype for population/phylogeographic comparisons (Smouse \& Chevillon 1998). In a test to determine the number of diagnosable clusters present in their microsatellite DNA data set using STRUCTURE, REA found the variability of likelihood estimates to be high, and concluded that the eight clusters identified by the analysis were poorly defined. This result is consistent with the findings of Pritchard et al. (2000) in which simulations found five loci were insufficient to resolve clusters. The 21 loci surveyed in the present study allowed identification of both deep and shallower levels of population structure, consequently resulting in six definable clusters. The present study also generated larger estimates of subspecies differentiation $\left(F_{\mathrm{ST}}, 0.11-\right.$ $\left.0.34 ; R_{\mathrm{ST}}, 0.17-0.78\right)$ than found in the previous study $\left(F_{\mathrm{ST}}\right.$, 0.01-0.16), which is consistent with the AMova that found a higher percentage of variation was distributed between subspecies (17.4\%) than reported by REA (7.5-8.9\%). The increased coverage of the nuclear genome afforded by the larger number of microsatellite loci yielded increased resolution of the phylogeographic structure present in Z. hudsonius. $\mathrm{R}_{\mathrm{ST}}$ differentiation observed among most of the subspecies is considerable, not of recent occurrence, and not simply the result of genetic drift.

The more than twofold differential in the estimate of variation between subspecies provided by $\Phi_{\mathrm{ST}}$ (this study) and $F_{\mathrm{ST}}$ (REA) broaches important issues regarding the conclusions drawn from the respective studies and underscores the fundamental differences between the two test statistics $\left(\Phi_{\mathrm{ST}}\right.$ and $\left.F_{\mathrm{ST}}\right)$ generated by AMOVA. $\Phi_{\mathrm{ST}}$ incorporates sequence divergence between haplotypes (providing the option of several distance metrics), as well as determining haplotype frequencies. Evolutionary differences among the haplotypes (i.e. mutations) are incorporated into calculations of the test statistics. $F_{\mathrm{ST}}$, which utilizes conventional F-statistics, treats all haplotypes, regardless of their evolutionary interrelationships, as equally differentiated (i.e. distance $=1.0$ ), and assesses variance distribution based on haplotype frequencies alone. Differences between haplotype frequencies are assumed to be due to genetic drift. Given that no haplotypes were shared among the five $Z$. hudsonius subspecies in the present study, $\Phi_{\mathrm{ST}}$ would appear to be the most appropriate statistic as $F_{\mathrm{ST}}$ values (a measure of haplotype frequencies only) have limited biological resolution or significance in this particular situation. When $\Phi_{\mathrm{ST}}$ and $F_{\mathrm{ST}}$ values are similar in magnitude, any population differentiation is likely due to genetic drift, but when $\Phi_{\mathrm{ST}}$ is large (as is the case for all subspecies comparisons in this study), regardless of the $F_{\mathrm{ST}}$, evolutionary depth in separations among haplotypes is implied. Moreover, if REA's critical test of uniqueness for Z. h. preblei mtDNA sequence data were applied (i.e. greater molecular variance be demonstrated between subspecies than within), the results obtained between all subspecies compared in the present study exceed this uniqueness test criterion (all $\Phi_{\mathrm{ST}}$ values were $>0.50$ ). By opting to utilize $F_{\mathrm{ST}}$ and failing to recognize the evolutionary differences among observed haplotypes, we contend that REA have utilized an inappropriate criterion for determining subspecies uniqueness.

For microsatellite DNA comparisons, REA's critical test of uniqueness for subspecies and historic genetic exchangeability was twofold: most variation was observed between subspecies in pairwise AMOvA comparisons (i.e. $F_{\mathrm{ST}} \geq 0.50$ ) and multiple private alleles are found at higher frequency than shared alleles at a majority of loci. These criteria often are not met among accepted species due to constraints on fixation indices generated from 
microsatellite DNA loci created by high heterozygosity levels and homoplasy (Hedrick 1999; Balloux et al. 2000). Although several $R_{\mathrm{ST}}$ values observed among the five subspecies compared in this study approached or exceeded the proposed criterion (Table 3), we contend the proposed criteria for microsatellite markers are unfounded because of the longer coalescent times associated with the nuclear genome (four times longer than mitochondrial DNA), and they likely have little biological meaning because a fundamental evolutionary process (e.g. mutation) is ignored.

In phylogeographic studies, principles of genealogical concordance have become a conceptual framework for identifying deeper units within a species (Ball \& Avise 1992; Avise 2000). Data presented here for Z. hudsonius subspecies are genealogically concordant in three out of four levels defined by Avise (2000): concordance between DNA characters (I); concordance between genomes (II); and concordance of gene tree partitions with independent biogeographic and systematic information (IV). First, there was concordance between the patterns of change in DNA sequences from the two mtDNA regions surveyed, seen in the similar, subspecies-specific patterns apparent in analyses of each gene region (Appendices D and E; Fig. 4) and from the fact that branch support for several nodes distinguishing subspecies increases, and becomes significant, when data sets are combined (Fig. 5a). The addition of more characters (e.g. cyt $b$ and CR) shows that there is more 'depth' to the divergence between Z.h. preblei, Z.h. campestris and Z.h. intermedius (i.e. greater number of inferred substitutions separating haplotypes and greater genetic distances) than examination of fewer bases of mtDNA revealed. Fine-scale patterns also become apparent, such as genetic structuring between northern and southern $Z$. $h$. preblei populations. Because intraspecific phylogeographic data sets are predisposed to have fewer informative characters and relationships between haplotypes are unlikely to be hierarchical in nature, traditional phylogenetic methods can lead to inadequately portrayed genealogical relationships (Brower et al. 1996). The haplotype network analysis adopted here depicted ancestral relationships and the nonrandom distribution of mutations among lineages, which resulted in the diagnostic haplotypic structure observed between subspecies and not observed in the more traditional parsimony analyses performed in this study or the distance-based approach utilized by REA. When forced into a phylogenetic comparison (e.g. parsimony analysis), $Z$.h. preblei, Z. h. campestris, and Z. h. intermedius exhibited shallow gene genealogies (at both CR and cyt $b$ ) - an intraspecific pattern consistent with ancestral polymorphism and incomplete lineage sorting; patterns that would be expected among recently diverged groups (Maddison 1997; Arbogast et al. 2002) and not uncommonly seen within rodent species (e.g. Peromyscus boylii, Tiemann-Boege et al. 2000; Neotoma floridana, Edwards \& Bradley 2001; Microtus agrestis, Jaarola \& Searle 2002). For the reason that evolution occurs at varying rates depending primarily on environmentaland demographic-based dynamics, we contend that sequence variation/divergence thresholds are inappropriate for intra or interspecific taxonomic designations. Alternatively, as genetic variation is apportioned among and within taxa, decisions on taxonomic recognition should be rendered on a case-by-case basis. Lastly, concordant patterns observed in the two mtDNA genes and nuclear microsatellites (Figs 2 and 3 ) are in agreement with the disjunct geographic distributions and morphological differences that led to the subspecies descriptions (Krutzsch 1954; Hafner et al. 1981) and lends confidence that actual evolutionary relationships have been recovered.

\section{Conservation implications}

Criteria chosen for delineating isolated intraspecific groupings (e.g. subspecies, phylogroups, distinct population segments, evolutionary significant units, designatable units, or management units) become of critical importance when the entity's continued existence is at risk (Moritz 1994b; Paetkau 1999). Given that the issue at hand constitutes an intraspecific comparison, we are concerned about the methodological pitfalls of applying approaches based on species-level inference. Mayr (1942) defined a subspecies as 'a geographically localized subdivision of the species, which differs genetically and taxonomically from other subdivisions of the species.' While this definition infers that subspecies have unique ranges and are diagnosable (Patten \& Unitt 2002), they are not necessarily reproductively isolated or they would qualify as species. Systematists have taken diverse positions on how 'taxonomically' may be interpreted. Some have asserted that this term infers long-term reproductive isolation and that the various components should be monophyletic (see Zink 2004 and references therein). Recently diverged intraspecific taxa can be characterized by multiple ancestral lineages at the time of divergence and might not exhibit reciprocal monophyly (Hudson \& Coyne 2002; Funk \& Omland 2003; Green 2005). We contend that since adaptation, diagnosability and biological speciation may exist well before achieving reproductive isolation and monophyly, these latter criteria have no basis under which to become standards for subspecies designation.

Similarly, genetic distinctness criteria that are inflexible represent a conservation stratagem that could impact the potential for future evolutionary change within the intraspecific unit of management and may lead to extirpation or extinction of discrete and evolutionarily significant intraspecific diversity. We found Ramey et al.'s (2005) core genetic-based criteria for Zapus hudsonius subspecies distinctness (i.e. greater variation between subspecies than within) to be (i) too stringent to account for relatively 
recently radiated taxa, (ii) scientifically unfounded as this criterion would not distinguish certain well-established species (Forbes et al. 1995; see Vignieri et al. 2006 and references therein), (iii) unachievable under some circumstances with the test statistics applied $\left(F_{\mathrm{ST}}\right.$; Hedrick 1999), and (iv) untenable given that important evolutionary processes (e.g. mutation) are disregarded. Consequently, these criteria should not be considered as an accepted standard when addressing ESA actions or for international conservation laws. Alternatively, we recommend application of the requirements for describing subspecies under the ESA proposed by Haig et al. (in press), which state that all such designations should meet the 'discreteness' and 'significance' criteria defined for listing a distinct population segment (DPS) under the Act.

The level of discontinuity observed among the subspecies in this study should not be considered minor or 'shallow' (Avise 2004) simply because the level of DNA sequence differentiation is relatively low, and not accompanied by the presence of reciprocal monophyly, demonstrable phenotypic divergence (but see Vignieri et al. 2006), or obvious adaptive significance. The differential magnitude observed between $\Phi_{\mathrm{ST}}$ (distance and frequency) and $F_{\mathrm{ST}}$ (frequency) values for both mtDNA CR and cyt $b$ suggests moderate micro-evolutionary depth among the five subspecies accompanied by phylogeographical structuring of haplotypes and multilocus genotypes within Z.h. preblei. The diagnostic nature of the haplotype variation between Z.h. preblei and other subspecies (there are no credible published data suggesting otherwise) and large degree of nuclear genetic differentiation at microsatellite loci suggests that these subspecies (and certain geographic populations within) have been reproductively isolated for such time that they appear to be on independent evolutionary trajectories, while having nearly achieved complete lineage sorting. We have identified strongly differentiated units of conservation (which could qualify as DPSs) that are entirely consistent with current taxonomy and support protection of the threatened population segment under the ESA. We conclude the subspecies surveyed in this study do not warrant synonymy, as proposed for Z.h. preblei, $Z$. h. campestris, and Z. h. intermedius; rather, they constitute distinct evolutionary lineages that merit separate management consideration, and those populations facing demographic challenges (e.g. Z. h. preblei-North, Z. h. preblei-South) should be afforded high conservation priority. The strong concurrence among patterns of mitochondrial and nuclear DNA variation observed in this study suggests that formal recognition of the relationships revealed will assist in preserving the potential for future evolutionary change within and among these subspecies.

A detailed comparison similar to that performed here for all subspecies of Z. hudsonius is warranted. Such a study would likely shed light on the significance of the con- siderable differentiation observed among the Z.h. preblei, $Z$.h. campestris, and Z.h. intermedius clade and will allow differentiation observed for Z.h. pallidus and Z. h. luteus to be observed in the best available context.

\section{Acknowledgements}

The authors are deeply indebted to: Tanya Shenk, Colorado Division of Wildlife and Robert Schorr, Colorado National Heritage Program for providing Z. hudsonius preblei tissue samples; and Cheryl Parmenter, Terry Yates, and the Division of Genomics Resources, Museum of Southwestern Biology, University of New Mexico, Albuquerque, New Mexico, Paula Cushing, Denver Museum of Nature and Science, Denver, Colorado, Robert Timm, University of Kansas Natural History Museum, Lawrence, Kansas, and Alex Schubert, Region 6, US Fish and Wildlife Service (USFWS) for provision of Zapus tissues. Field assistance was kindly provided by Laura Ellison, J.P. Farrar, Keith Geluso, Britta Schielke, and Ernie Valdez. Sampling by USGS field crews would not have been possible without the help of: Doug Backlund, South Dakota Department of Game, Fish, and Parks; Cara Staab, Black Hills National Forest, USFS; Tom Koerner, Shilo ComeauxKingfisher, and Scott Gonnion, Lacreek National Wildlife Refuge; Tom Whitford and Rhonda O'Byrne, Custer National Forest; Eugene Williams, Sand Lake National Wildlife Refuge; Martin Grenier, Wyoming Game and Fish Department; and Jerry Pecha, Nebraska Game and Parks Division. The authors would like to thank Fred Allendorf, Peter Dratch, Steve Chambers, Laurent Excoffier, Guillaume Laval, Brian Bowen, Peter Smouse, and Joseph Quattro for helpful discussions regarding study design and statistical analysis. David Hafner, Eric Hallerman, Andrew Martin, Sara Oyler-McCance, Ed Pendleton, Sacha Vignieri, and Rocky Ward provided constructive comments on the first draft of this manuscript. Ronald Adkins, Joel Cracraft, Hopi Hoekstra, Maarit Jaarola, Kim Scribner, Robin Waples, and Mike Wooten provided substantive peer reviews of a later draft. The authors are enormously indebted to all of these scientists for their unselfish efforts to improve this presentation. The authors thank Robin Johnson for laboratory assistance and Anne Henderson for assistance with editing. This project was jointly funded by the USFWS, US Geological Survey (USGS)-Leetown Science Center's Aquatic Ecology Branch, and the USGS Science Support Program. Lastly, the authors wish to thank Dr Loren Rieseberg and three anonymous reviewers for their constructive criticisms and meaningful contributions to this manuscript.

\section{References}

Adams RI, Brown KM, Hamilton MB (2004) The impact of microsatellite electromorph size homoplasy on multilocus population structure estimates in a tropical tree (Corythophora alta) and an anadromous fish (Morone saxatilis). Molecular Ecology, 13, 25792588.

Anderson KW, Jones JK (1971) Mammals of northwestern South Dakota. University of Kansas Publications, Museum of Natural History, 19, 361-393.

Arbogast BS, Edwards SV Wakeley J Beerli P Slowinski JB (2002) Estimating divergence times from molecular data on phylogenetic and population genetic timescales. Annual Review of Ecology and Systematics, 33, 707-740. 
Avise JC (2000) Phylogeography. Harvard University Press, Cambridge, Massachusetts.

Avise JC (2004) Molecular Markers, Natural History, and Evolution,

2nd edn. Sinauer Associates, Sunderland, Massachusetts.

Avise JC, Ball RM (1990) Principles of genealogical concordance in species concepts and biological taxonomy. In: Oxford Surveys in Evolutionary Biology (eds Futuyma D Antonovics J), pp. 45-67. Oxford University Press, Oxford.

Ball RM, Avise JC (1992) Mitochondrial DNA phylogeographic differentiation among avian populations and the evolutionary significance of subspecies. Auk, 109, 626-636.

Balloux F, Brunner H, Lugon-Moulin N, Hausser J, Goudet J (2000) Microsatellites can be misleading: an empirical and simulation study. Evolution, 54, 1414-1422.

Baverstock PR, Moritz C (1996) Project design. In: Molecular Systematics (eds Hillis DM, Mortiz C, Mable BK), 2nd edn, pp. 17-27. Sinauer Associates, Sunderland, Massachusetts.

Beaumont MA, Nichols RA (1996) Evaluating loci for use in the genetic analysis of population structure. Proceedings of the Royal Society of London. Series B, Biological Sciences, 263, 1619-1626.

Bremer K (1988) The limits of amino acid sequence data in angiosperm phylogenetic reconstruction. Evolution, 42, 795-803.

Bremer K (1994) Branch support and tree stability. Cladistics, 10, 295-304.

Brower AVZ, DeSalle R, Vogler A (1996) Gene trees, species trees, and systematics. Annual Review of Ecology and Systematics, 27, 423-450.

Clark CM, Wentworth TR, O'Malley DM (2000) Genetic discontinuity revealed by chloroplast microsatellites in eastern North American Abies (Pinaceae). American Journal of Botany, 87, 774-782.

Clement M, Posada D, Crandall KA (2000) TCS: a computer program to estimate gene genealogies. Molecular Ecology, 9, 1657-1659.

Conner MM, Shenk TM (2003) Distinguishing Zapus hudsonius preblei from Zapus princeps princeps by using repeated cranial measurements. Journal of Mammalogy, 84, 1456-1463.

Crandall KA, Templeton AR, Sing CF (1994) Intraspecific cladogram estimation: problems and solutions. In: Models in Phylogeny Reconstruction (eds Scotland RW, Siebert DJ, Williams DM), pp. 273-297. Clarendon Press, Oxford.

Edwards CW, Bradley RD (2001) Molecular phylogenetics of the Neotoma floridana species group. Journal of Mammalogy, 82, 791-798.

El Mousadik A, Petit RJ (1996) High level of genetic differentiation for allelic richness among populations of the argan tree [Argania spinosa (L.) Skeels] endemic of Morocco. Theoretical and Applied Genetics, 92, 832-839.

Evanno G, Regnaut S, Goudet J (2005) Detecting the number of clusters of individuals using the software STRUCTURE: a simulation study. Molecular Ecology, 14, 2611-2620.

Excoffier L, Smouse PE, Quattro JM (1992) Analysis of molecular variance inferred from metric distances among DNA haplotypes: application to human mitochondrial DNA restriction data. Genetics, 131, 479-491.

Farris JS, Kallersjo M, Kluge AJ, Bult C (1994) Testing significance of incongruence. Cladistics, 10, 315-319.

Felsenstein J (1985) Confidence limits on phylogenies: an approach using the bootstrap. Evolution, 39, 783-791.

Forbes HS, Hogg JT, Buchanan FC, Crawford AM, Allendorf FW (1995) Microsatellite evolution in congenerics mammals: Domestic and Bighorn sheep. Molecular Biology and Evolution, 12, 1106-1113.

Funk DJ, Omland KE (2003) Species-level paraphyly and polyphyly: frequency, causes, and consequences, with insights from animal mitochondrial DNA. Annual Review of Ecology, Evolution, and Systematics, 34, 397-423.

Goudet J (1995) FSTAT (Version 1.2): a computer program to calculate F statistics. Journal of Heredity, 86, 485-486.

Grant WS (1987) Genetic divergence between congeneric Atlantic and Pacific Ocean fishes. In: Population Genetics and Fishery Management (eds Ryman N, Utter F), pp. 225-246. University of Washington Press, Seattle, Washington.

Green DM (2005) Designatable units for status assessment of endangered species. Conservation Biology, 19, 1813-1820.

Guo SW, Thompson EA (1992) Performing the exact test of HardyWeinberg proportions for multiple alleles. Biometrics, 48, 361-372.

Hafner DJ, Peterson KE, Yates TL (1981) Evolutionary relationships of jumping mice (Genus Zapus) of the southwestern United States. Journal of Mammalogy, 62, 501-512.

Haig SM, Beever EA, Chambers SM et al. (in press) Review: taxonomic considerations in listing subspecies under the U.S. Endangered Species Act. Conservation Biology.

Hedrick PW (1999) Perspective: highly variable loci and their interpretation in evolution and conservation. Evolution, 53, 313-318.

Hudson RR, Coyne JA (2002) Mathematical consequences of the genealogical species concept. Evolution, 56, 1557-1565.

Huelsenbeck JP, Ronquist F (2001) MRBAYEs: Bayesian inference of phylogenetic trees. Bioinformatics, 17, 754-755.

Iudica W, Whitten M, Williams NH (2001) Small bones from dried mammal museum specimens as a reliable source of DNA. BioTechniques, 30, 732-736.

Jaarola M, Searle JB (2002) Phylogeography of field voles (Microtus agresti) in Eurasia inferred from mitochondrial DNA sequences. Molecular Ecology, 11, 2613-2621.

Jones GS (1981) The systematics and biology of the genus Zapus (Mammalia, Rodentia, Zapodidae). PhD Thesis, Indiana State University, Indiana.

Jones JK, Armstrong DM, Hoffmann RS, Jones C (1983) Mammals of the Northern Great Plains. University of Nebraska Press, Lincoln, Nebraska.

Katti MV, Ranjekar PK, Gupta VS (2001) Differential distribution of simple sequence repeats in eukaryotic genome sequences. Molecular Biology and Evolution, 18, 1161-1167.

King TL, Eackles MS, Young CC (2006) Microsatellite DNA markers for assessing phylogeographic and population structure in Preble's meadow jumping mice (Zapus hudsonius preblei) and cross-amplification among neighboring taxa. Molecular Ecology Notes, 6, 670-637.

King TL, Lubinski BA, Spidle AP (2001) Microsatellite DNA variation in Atlantic sturgeon (Acipenser oxyrinchus oxyrinchus) and cross-species amplification in the Acipenseridae. Conservation Genetics, 2, 103-119.

Kirchman JJ, Hackett SJ, Goodman SM, Bates JM (2001) Phylogeny and systematics of ground rollers (Brachypteraciidae) of Madagascar. Auk, 118, 849-863.

Kocher TD, Thomas WK, Meyer RA et al. (1989) Dynamics of mitochondrial DNA evolution in animals - amplification and sequencing with conserved primers. Proceedings of the National Academy of Sciences, USA, 86, 6196-6200.

Krutzsch PH (1954) North American jumping mice (genus Zapus). University of Kansas Publication Museum of Natural History, 4, 349-472.

Maddison WP (1997) Gene trees in species trees. Systematic Biology, 46, 523-536.

Mayr E (1942) Systematics and the Origin of Species. Columbia University Press, New York. 
Moritz C (1994a) Applications of mitochondrial DNA analysis in conservation: a critical review. Molecular Ecology, 3, 401-411.

Moritz C (1994b) Defining 'evolutionarily significant units' for conservation. Trends in Ecology and Evolution, 9, 373-375.

Moritz C, Hillis DM (1996) Molecular systematics: context and controversies. In: Molecular Systematics (eds Hillis DM, Mortiz C, Mable BK), 2nd edn, pp. 1-13. Sinauer Associates, Sunderland, Massachusetts.

Nei M, Tajima F, Tateno Y (1983) Accuracy of estimated phylogenetic trees from molecular data. Journal of Molecular Evolution, 19, 153-170.

Paetkau D (1999) Using genetics to identify intraspecific conservation units: a critique of current methods. Conservation Biology, 13, 1507-1509.

Page RDM (1996) TREEviEw: an application to display phylogenetic trees on personal computers. Computer Applications in the Biosciences, 12, 357-358.

Patten MA, Unitt P (2002) Diagnosability versus mean differences of Sage Sparrow subspecies. Auk, 119, 26-35.

Posada D, Crandall KA (2001) Selecting the best-fit model of nucleotide substitution. Systematic Biology, 50, 580-601.

Preble EA (1899) Revision of the jumping mice of the genus Zapus. North American Fauna, 15, 1-41.

Pritchard JK, Rosenberg NA (1999) Use of unlinked genetic markers to detect population stratification in association studies. American Journal of Human Genetics, 65, 220-228.

Pritchard JK, Stephens M, Donnelly P (2000) Inference of population structure using multilocus genotype data. Genetics, 155, 945-959.

Ramey RR, Liu HP, Epps CW, Carpenter LM, Weshausen JD (2005) Genetic relatedness of the Preble's meadow jumping mouse (Zapus hudsonius preblei) to nearby subspecies of Z. hudsonius as inferred from variation in cranial morphology, mitochondrial DNA and microsatellite DNA: implications for taxonomy and conservation. Animal Conservation, 8, 329-346.

Raymond M, Rousset F (1995) GENEPOP (version 1.2): population genetics software for exact tests and ecumenicism. Journal of Heredity, 86, 248-249.

Rice WR (1989) Analyzing tables of statistical tests. Evolution, 43, 223-225.

Schneider S, Roessli D, Excoffier L (2000) ARLEQUIN: a Software for Population Genetics Data Analysis. University of Geneva, Genetics and Biometry Laboratory, Geneva, Switzerland.

Shields GF, Kocher TD (1991) Phylogenetic relationships of North American Ursids based on analysis of mitochondrial-DNA. Evolution, 45, 218-221.

Smouse PE, Chevillon C (1998) Analytical aspects of populationspecific DNA fingerprinting for individuals. Journal of Heredity, 89, 143-150.

Sokal RR, Rohlf ZJ (1994) Biometry: the Principles and Practice of Statistics in Biology Research, 3rd edn. W.H. Freeman, New York.

Sorenson MD (1999) TREEROT, version 2. Boston University, Boston, Massachusetts.

Steinberg EK (1999) Characterization of polymorphic microsatellites from current and historic populations of North American pocket gophers (Geomyidae: Thomomys). Molecular Ecology, 8, 1075-1092.

Swofford DL (2002) PAUP*: Phylogenetic Analysis Using Parsimony (*and Other Methods), Version 4.0. Sinauer Associates, Sunderland, Massachusetts.

Swofford DL, Selander RB (1981) BIOsYs-1: a Fortran program for the comprehensive analysis of electrophoretic data in population genetics and systematics. Journal of Heredity, 72, 282-283.
Takezaki N, Nei M (1996) Genetic distances and reconstruction of phylogenetic trees from microsatellite DNA. Genetics, 144, 389399.

Tamura K, Nei M (1993) Estimation of the number of nucleotide substitutions in the control region of mitochondrial DNA in humans and chimpanzees. Molecular Biology and Evolution, 10, 512-526.

Templeton AR, Crandall KA, Sing CF (1992) A cladistic analysis of phenotypic associations with haplotypes inferred from restriction endonuclease mapping and DNA sequence data. III. Cladogram estimation. Genetics, 132, 619-633.

Thompson JD, Higgins DG, Gibson TJ (1994) CLUstal w: improving the sensitivity of progressive multiple sequence alignment through sequence weighting, position-specific gap penalties and weight matrix choice. Nucleic Acids Research, 22, 46734680.

Tiemann-Boege I, Kilpatrick CW, Schmidly DJ, Bradley RD (2000) Molecular phylogenetics of the Peromyscus boylii species group (Rodentia: Muridae) based on mitochondrial cytochrome $b$ sequences. Molecular Phylogenetics and Evolution, 16, 366-378.

US Fish and Wildlife Service (1998) Final rule to list the Preble's meadow jumping mouse as a threatened species. The Federal Register, 53, 26517-26530.

US Fish and Wildlife Service (2005) Endangered and threatened wildlife and plants; 12 -month finding on a petition to delist the Preble's meadow jumping mouse (Zapus hudsonius preblei) and proposed delisting of the Preble's meadow jumping mMouse. The Federal Register, 70, 5404-5411.

Vignieri SN (2003) Isolation and characterization of eight highly variable microsatellite markers in the Pacific jumping mouse (Zapus trinotatus). Molecular Ecology Notes, 3, 638-640.

Vignieri SN (2005) Streams over mountains: influence of riparian connectivity on gene flow in the Pacific jumping mouse (Zapus trinotatus). Molecular Ecology, 14, 1925-1937.

Vignieri SN, Hallerman EM, Bergstrom BJ et al. (2006) Mistaken view of taxonomic validity undermines conservation of an evolutionarily distinct mouse: a response to Ramey et al. (2005). Animal Conservation. Published online 10 May 2006.

Weir BS, Cockerham CC (1984) Estimating F-statistics for the analysis of population structure. Evolution, 38, 1358-1370.

Zink RM (2004) The role of subspecies in obscuring avian biological diversity and misleading conservation policy. Proceedings of the Royal Society of London. Series B, Biological Sciences, 271, 561-564.

Tim King's research emphasis involves the application of molecular genetic markers to the phylogenetics, phylogeography, population structure, and captive breeding management of declining species. This contribution is yet another effort to assist natural resource managers with guidance in identifying appropriate units of conservation. John Switzer is working in King's laboratory with research interests that include systematics, phylogeography and conservation genetics. Cheryl Morrison is working in King's laboratory with research interests in the fields of evolutionary and conservation genetics, including molecular systematics and taxonomy issues, phylogeography, and population genetics. Mike Eackles, Colleen Young, and Barbara Lubinski are biologists that specialize in DNA fragment and sequence analyses in King's laboratory. Paul Cryan's research focuses on the ecology, behavior, and biogeography of at-risk species of mammals. 


\section{Appendix A}

Listing of Zapus hudsonius museum specimens used in the present study including the museum identifier, the USGS individual identifier, the abbreviated collection name (Table 1), the county and state each specimen was collected, and the subspecies designation. Tissues of specimens from three museums were utilized: Denver Museum of Nature and Science, Denver, Colorado; University of Kansas, Natural History Museum, Lawrence, Kansas, and the University of New Mexico, Museum of Southwestern Biology, Albuquerque, New Mexico

\begin{tabular}{|c|c|c|c|c|c|}
\hline Museum identifier & Individual identifier & Study collection & County & State & Designated subspecies \\
\hline \multicolumn{6}{|c|}{ Denver Museum of Nature and Science } \\
\hline CHG9901 & CHG9901 & SOWY & Laramie & Wyoming & preblei \\
\hline CTA9802 & CTA9802 & SOWY & Albany & Wyoming & preblei \\
\hline CTN9901 & CTN9901 & SOWY & Albany & Wyoming & preblei \\
\hline DOU9901 & DOU9901 & SOWY & Converse & Wyoming & preblei \\
\hline DUC9901 & DUC9901 & SOWY & Albany & Wyoming & preblei \\
\hline ELB9901 & ELB9901 & SOWY & Laramie & Wyoming & preblei \\
\hline ELB9902 & ELB9902 & SOWY & Laramie & Wyoming & preblei \\
\hline ЕРВ9901 & ЕРВ9901 & SOWY & Laramie & Wyoming & preblei \\
\hline FRC9802 & FRC9802 & SOWY & Albany & Wyoming & preblei \\
\hline LUM9901 & LUM9901 & SOWY & Platte & Wyoming & preblei \\
\hline LUM9902 & LUM9902 & SOWY & Platte & Wyoming & preblei \\
\hline LUM9903 & LUM9903 & SOWY & Platte & Wyoming & preblei \\
\hline MCW9901 & MCW9901 & SOWY & Albany & Wyoming & preblei \\
\hline MCW9902 & MCW9902 & SOWY & Albany & Wyoming & preblei \\
\hline NLR9901 & NLR9901 & SOWY & Albany & Wyoming & preblei \\
\hline NSB9901 & NSB9901 & SOWY & Laramie & Wyoming & preblei \\
\hline RBC9901 & RBC9901 & SOWY & Platte & Wyoming & preblei \\
\hline SBC9901 & SBC9901 & SOWY & Laramie & Wyoming & preblei \\
\hline SSC9901 & SSC9901 & SOWY & Albany & Wyoming & preblei \\
\hline SSC9902 & SSC9902 & SOWY & Albany & Wyoming & preblei \\
\hline SSC 9903 & SSC9903 & SOWY & Albany & Wyoming & preblei \\
\hline SYB9901 & SYB9901 & SOWY & Platte & Wyoming & preblei \\
\hline YCA9806 & YCA9806 & SOWY & Laramie & Wyoming & preblei \\
\hline YCA9807 & YCA9807 & SOWY & Laramie & Wyoming & preblei \\
\hline YCB9801 & YCB9801 & SOWY & Laramie & Wyoming & preblei \\
\hline YCB9802 & YCB9802 & SOWY & Laramie & Wyoming & preblei \\
\hline YCB9803 & YCB9803 & SOWY & Laramie & Wyoming & preblei \\
\hline YCB9804 & YCB9804 & SOWY & Laramie & Wyoming & preblei \\
\hline CER-9801 & CER-9801 & LCCO1 & Larimer & Colorado & preblei \\
\hline CER-9802 & CER-9802 & LCCO1 & Larimer & Colorado & preblei \\
\hline CER-9803 & CER-9803 & LCCO1 & Larimer & Colorado & preblei \\
\hline CER-9804 & CER-9804 & LCCO1 & Larimer & Colorado & preblei \\
\hline CER-9805 & CER-9805 & LCCO1 & Larimer & Colorado & preblei \\
\hline CER-9806 & CER-9806 & LCCO1 & Larimer & Colorado & preblei \\
\hline HRK-9801 & HRK-9801 & LCCO1 & Larimer & Colorado & preblei \\
\hline HRK-9802 & HRK-9802 & LCCO1 & Larimer & Colorado & preblei \\
\hline HRK-9803 & HRK-9803 & LCCO1 & Larimer & Colorado & preblei \\
\hline HRK-9804 & HRK-9804 & LCCO1 & Larimer & Colorado & preblei \\
\hline CP9806, random \# 205 & CP-205 & LCCO1 & Larimer & Colorado & preblei \\
\hline MC-9801 & MC-9801 & LCCO1 & Larimer & Colorado & preblei \\
\hline MC-9803 & MC-9803 & LCCO1 & Larimer & Colorado & preblei \\
\hline NFP-9801 & NFP-9801 & LCCO1 & Larimer & Colorado & preblei \\
\hline NFP-9802 & NFP-9802 & LCCO1 & Larimer & Colorado & preblei \\
\hline BG-9801 & BG-9801 & $\mathrm{LCCO} 2$ & Larimer & Colorado & preblei \\
\hline BG-9802 & BG-9802 & $\mathrm{LCCO} 2$ & Larimer & Colorado & preblei \\
\hline PGC-9801 & PGC-9801 & LCCO2 & Larimer & Colorado & preblei \\
\hline SP9803, random \# 125 & SP-125 & LCCO2 & Larimer & Colorado & preblei \\
\hline SP9802, random \# 169 & SP-169 & LCCO2 & Larimer & Colorado & preblei \\
\hline SP9805, Random \# 170 & SP-170 & $\mathrm{LCCO} 2$ & Larimer & Colorado & preblei \\
\hline SP9807, Random \# 223 & SP-223 & $\mathrm{LCCO} 2$ & Larimer & Colorado & preblei \\
\hline
\end{tabular}


4352 T. L. KING ET AL.

Appendix A Continued

\begin{tabular}{|c|c|c|c|c|c|}
\hline Museum identifier & Individual identifier & Study collection & County & State & Designated subspecies \\
\hline SP9804, Random \# 243 & SP-243 & $\mathrm{LCCO} 2$ & Larimer & Colorado & preblei \\
\hline SP9806, Random \# 336 & SP-336 & $\mathrm{LCCO} 2$ & Larimer & Colorado & preblei \\
\hline SP9812, Random \# 367 & SP-367 & LCCO2 & Larimer & Colorado & preblei \\
\hline SP9810, Random \# 375 & SP-375 & $\mathrm{LCCO} 2$ & Larimer & Colorado & preblei \\
\hline SP9811, Random \# 674 & SP-674 & LCCO2 & Larimer & Colorado & preblei \\
\hline SP9801, Random \# 746 & SP-746 & $\mathrm{LCCO} 2$ & Larimer & Colorado & preblei \\
\hline SP9809, Random \# 861 & SP-861 & $\mathrm{LCCO} 2$ & Larimer & Colorado & preblei \\
\hline YG-9801 & YG-9801 & LCCO2 & Larimer & Colorado & preblei \\
\hline YG-9803 & YG-9803 & LCCO2 & Larimer & Colorado & preblei \\
\hline MA98133, Random \# 127 & MAY-127 & DCCO1 & Douglas & Colorado & preblei \\
\hline MA9809, Random \# 165 & MAY-165 & DCCO1 & Douglas & Colorado & preblei \\
\hline MA98122, Random \# 215 & MAY-215 & DCCO1 & Douglas & Colorado & preblei \\
\hline MA98201, Random \# 229 & MAY-229 & DCCO1 & Douglas & Colorado & preblei \\
\hline MA98135, Random \# 234 & MAY-234 & DCCO1 & Douglas & Colorado & preblei \\
\hline MA9801, Random \# 254 & MAY-254 & DCCO1 & Douglas & Colorado & preblei \\
\hline MA98104, Random \# 268 & MAY-268 & DCCO1 & Douglas & Colorado & preblei \\
\hline MA98108, Random \# 281 & MAY-281 & DCCO1 & Douglas & Colorado & preblei \\
\hline MA98134, Random \# 368 & MAY-368 & DCCO1 & Douglas & Colorado & preblei \\
\hline MA98132, Random \# 374 & MAY-374 & DCCO1 & Douglas & Colorado & preblei \\
\hline MA9802, Random \# 385 & MAY-385 & DCCO1 & Douglas & Colorado & preblei \\
\hline MA98136, Random \# 408 & MAY-408 & DCCO1 & Douglas & Colorado & preblei \\
\hline MA98120, Random \# 416 & MAY-416 & DCCO1 & Douglas & Colorado & preblei \\
\hline MA98130, Random \# 429 & MAY-429 & DCCO1 & Douglas & Colorado & preblei \\
\hline MA98138, Random \# 452 & MAY-452 & DCCO1 & Douglas & Colorado & preblei \\
\hline MA98131, Random \# 494 & MAY-494 & DCCO1 & Douglas & Colorado & preblei \\
\hline MA98124, Random \# 497 & MAY-497 & DCCO1 & Douglas & Colorado & preblei \\
\hline MA98121, Random \# 517 & MAY-517 & DCCO1 & Douglas & Colorado & preblei \\
\hline MA98102, Random \# 532 & MAY-532 & DCCO1 & Douglas & Colorado & preblei \\
\hline MA98106, Random \# 694 & MAY-694 & DCCO1 & Douglas & Colorado & preblei \\
\hline MA98204, Random \# 706 & MAY-706 & DCCO1 & Douglas & Colorado & preblei \\
\hline MA98107, Random \# 714 & MAY-714 & DCCO1 & Douglas & Colorado & preblei \\
\hline MA98123, Random \# 748 & MAY-748 & DCCO1 & Douglas & Colorado & preblei \\
\hline MA9805, Random \# 785 & MAY-785 & DCCO1 & Douglas & Colorado & preblei \\
\hline MA9810, Random \# 798 & MAY-798 & DCCO1 & Douglas & Colorado & preblei \\
\hline MA98103, Random \# 817 & MAY-817 & DCCO1 & Douglas & Colorado & preblei \\
\hline MA98203, Random \# 822 & MAY-822 & DCCO1 & Douglas & Colorado & preblei \\
\hline MA9804, Random \# 880 & MAY-880 & DCCO1 & Douglas & Colorado & preblei \\
\hline MA9806, Random \# 933 & MAY-933 & DCCO1 & Douglas & Colorado & preblei \\
\hline MA98137, Random \# 940 & MAY-940 & DCCO1 & Douglas & Colorado & preblei \\
\hline MA98202, Random \# 946 & MAY-946 & DCCO1 & Douglas & Colorado & preblei \\
\hline MA9811, Random \# 964 & MAY-964 & DCCO1 & Douglas & Colorado & preblei \\
\hline MA9813 & MAY-9813 & DCCO1 & Douglas & Colorado & preblei \\
\hline MA9814 & MAY-9814 & DCCO1 & Douglas & Colorado & preblei \\
\hline WH9801, Random \# 715 & WH-9801 & DCCO2 & Douglas & Colorado & preblei \\
\hline WH9802, Random \# 911 & WH-9802 & DCCO2 & Douglas & Colorado & preblei \\
\hline WH9803, Random \# 629 & WH-9803 & $\mathrm{DCCO} 2$ & Douglas & Colorado & preblei \\
\hline WH9804, Random \# 675 & WH-9804 & $\mathrm{DCCO} 2$ & Douglas & Colorado & preblei \\
\hline WH9805, Random \# 849 & WH-9805 & DCCO2 & Douglas & Colorado & preblei \\
\hline WH9806, Random \# 961 & WH-9806 & $\mathrm{DCCO} 2$ & Douglas & Colorado & preblei \\
\hline WH98100, Random \# 573 & WH-98100 & $\mathrm{DCCO} 2$ & Douglas & Colorado & preblei \\
\hline WH98101, Random \# 789 & WH-98101 & DCCO2 & Douglas & Colorado & preblei \\
\hline WH98102, Random \# 672 & WH-98102 & DCCO2 & Douglas & Colorado & preblei \\
\hline WH98103, Random \# 884 & WH-98103 & DCCO2 & Douglas & Colorado & preblei \\
\hline WH98104, Random \# 719 & WH-98104 & $\mathrm{DCCO} 2$ & Douglas & Colorado & preblei \\
\hline WH98105, Random \# 635 & WH-98105 & $\mathrm{DCCO} 2$ & Douglas & Colorado & preblei \\
\hline WH98106, Random \# 603 & WH-98106 & DCCO2 & Douglas & Colorado & preblei \\
\hline
\end{tabular}


Appendix A Continued

\begin{tabular}{|c|c|c|c|c|c|}
\hline Museum identifier & Individual identifier & Study collection & County & State & Designated subspecies \\
\hline WH98107, Random \# 716 & WH-98107 & DCCO2 & Douglas & Colorado & preblei \\
\hline WH98108, Random \# 208 & WH-98108 & DCCO2 & Douglas & Colorado & preblei \\
\hline WH98109, Random \# 958 & WH-98109 & DCCO2 & Douglas & Colorado & preblei \\
\hline WH98110, Random \# 543 & WH-98110 & $\mathrm{DCCO} 2$ & Douglas & Colorado & preblei \\
\hline WH98120, Random \# 768 & WH-98120 & $\mathrm{DCCO} 2$ & Douglas & Colorado & preblei \\
\hline WH98121, Random \# 113 & WH-98121 & $\mathrm{DCCO} 2$ & Douglas & Colorado & preblei \\
\hline WH98300, Random \# 140 & WH-98300 & $\mathrm{DCCO} 2$ & Douglas & Colorado & preblei \\
\hline WH98301, Random \# 204 & WH-98301 & DCCO2 & Douglas & Colorado & preblei \\
\hline WH98302, Random \# 814 & WH-98302 & $\mathrm{DCCO} 2$ & Douglas & Colorado & preblei \\
\hline WH98303, Random \# 610 & WH-98303 & DCCO2 & Douglas & Colorado & preblei \\
\hline WH98304, Random \# 190 & WH-98304 & DCCO2 & Douglas & Colorado & preblei \\
\hline WH98305, Random \# 314 & WH-98305 & DCCO2 & Douglas & Colorado & preblei \\
\hline WH98306, Random \# 612 & WH-98306 & $\mathrm{DCCO} 2$ & Douglas & Colorado & preblei \\
\hline WH98309, Random \# 120 & WH-98309 & $\mathrm{DCCO} 2$ & Douglas & Colorado & preblei \\
\hline WH98311, Random \# 860 & WH-98311 & $\mathrm{DCCO} 2$ & Douglas & Colorado & preblei \\
\hline WH98312, Random \# 883 & WH-98312 & $\mathrm{DCCO} 2$ & Douglas & Colorado & preblei \\
\hline WH98313, Random \# 924 & WH-98313 & $\mathrm{DCCO} 2$ & Douglas & Colorado & preblei \\
\hline MCA9801 & Zhp-01 & ECCO1 & El Paso & Colorado & preblei \\
\hline MCA9805 & Zhp-03 & ECCO1 & El Paso & Colorado & preblei \\
\hline MCA9806 & Zhp-04 & ECCO1 & El Paso & Colorado & preblei \\
\hline 98КC01 & Zhp-05 & ECCO1 & El Paso & Colorado & preblei \\
\hline 98 PV01 & Zhp-06 & ECCO1 & El Paso & Colorado & preblei \\
\hline 98SC01 & Zhp-07 & ECCO1 & El Paso & Colorado & preblei \\
\hline 98SC02 & Zhp-08 & ECCO1 & El Paso & Colorado & preblei \\
\hline 98SC03 & Zhp-09 & ECCO1 & El Paso & Colorado & preblei \\
\hline 98SC04 & Zhp-10 & ECCO1 & El Paso & Colorado & preblei \\
\hline 98SC05 & Zhp-11 & ECCO1 & El Paso & Colorado & preblei \\
\hline 98SC07 & Zhp-13 & ECCO1 & El Paso & Colorado & preblei \\
\hline DMC01 & Zhp-15 & ECCO1 & El Paso & Colorado & preblei \\
\hline DMC02 & Zhp-16 & ECCO1 & El Paso & Colorado & preblei \\
\hline BS0198 & Zhp-17 & ECCO1 & El Paso & Colorado & preblei \\
\hline BS0298 & Zhp-18 & ECCO1 & El Paso & Colorado & preblei \\
\hline LR0198 & Zhp-19 & ECCO1 & El Paso & Colorado & preblei \\
\hline LR0298 & Zhp-20 & ECCO1 & El Paso & Colorado & preblei \\
\hline LR0398 & Zhp-21 & ECCO1 & El Paso & Colorado & preblei \\
\hline DC9802 & Zhp-23 & ECCO1 & El Paso & Colorado & preblei \\
\hline DC9803 & Zhp-24 & ECCO1 & El Paso & Colorado & preblei \\
\hline DC9804 & Zhp-25 & ECCO1 & El Paso & Colorado & preblei \\
\hline DC9805 & Zhp-26 & ECCO1 & El Paso & Colorado & preblei \\
\hline GCC0198 & Zhp-27 & ECCO1 & El Paso & Colorado & preblei \\
\hline \multicolumn{6}{|c|}{ University of Kansas Natural History Museum } \\
\hline KU109972 & Zhc-116 & NA & Custer & South Dakota & campestris \\
\hline KU109963 & Zhc-124 & NA & Lawrence & South Dakota & campestris \\
\hline KU109978 & Zhc-117 & NA & Custer & South Dakota & campestris \\
\hline KU109984 & Zhc-118 & NA & Custer & South Dakota & campestris \\
\hline KU109985 & Zhc-119 & NA & Custer & South Dakota & campestris \\
\hline KU110013 & Zhc-115 & NA & Custer & South Dakota & campestris \\
\hline KU123592 & Zhc-097 & NA & Carter & Montana & campestris \\
\hline KU123597 & Zhc-095 & NA & Carter & Montana & campestris \\
\hline KU112661 & Zhc-126 & NA & Lawrence & South Dakota & campestris \\
\hline KU112663 & Zhc-127 & NA & Lawrence & South Dakota & campestris \\
\hline KU115700 & Zhi-033 & NA & Burleigh & North Dakota & intermedius \\
\hline KU115730 & Zhi-037 & NA & Walworth & South Dakota & intermedius \\
\hline KU112665 & Zhc-128 & NA & Lawrence & South Dakota & campestris \\
\hline KU153706 & Zhpa-050 & NA & Leavenworth & Kansas & pallidus \\
\hline KU110033 & Zhpa-051 & NA & Bennett & South Dakota & pallidus \\
\hline
\end{tabular}


4354 T. L. KING ET AL.

Appendix A Continued

\begin{tabular}{|c|c|c|c|c|c|}
\hline Museum identifier & Individual identifier & Study collection & County & State & Designated subspecies \\
\hline \multicolumn{6}{|c|}{ Museum of Southwestern Biology, University of New Mexico } \\
\hline None & MSB-41518 & MCMN & Morrison & Minnesota & intermedius \\
\hline 84916 & MSB-41532 & MCMN & Morrison & Minnesota & intermedius \\
\hline 84917 & MSB-41533 & MCMN & Morrison & Minnesota & intermedius \\
\hline 90860 & MSB-80766 & MCMN & Morrison & Minnesota & intermedius \\
\hline 90861 & MSB-80767 & MCMN & Morrison & Minnesota & intermedius \\
\hline 90862 & MSB-80768 & MCMN & Morrison & Minnesota & intermedius \\
\hline 90863 & MSB-80769 & MCMN & Morrison & Minnesota & intermedius \\
\hline 90864 & MSB-80770 & MCMN & Morrison & Minnesota & intermedius \\
\hline 90865 & MSB-80771 & MCMN & Morrison & Minnesota & intermedius \\
\hline 90866 & MSB-80772 & MCMN & Morrison & Minnesota & intermedius \\
\hline 90867 & MSB-80773 & MCMN & Morrison & Minnesota & intermedius \\
\hline 90868 & MSB-80774 & MCMN & Morrison & Minnesota & intermedius \\
\hline 90869 & MSB-80778 & MCMN & Morrison & Minnesota & intermedius \\
\hline 90870 & MSB-80779 & MCMN & Morrison & Minnesota & intermedius \\
\hline 90871 & MSB-80780 & MCMN & Morrison & Minnesota & intermedius \\
\hline 90872 & MSB-80781 & MCMN & Morrison & Minnesota & intermedius \\
\hline 90873 & MSB-80782 & MCMN & Morrison & Minnesota & intermedius \\
\hline 90874 & MSB-80783 & MCMN & Morrison & Minnesota & intermedius \\
\hline 90875 & MSB-80784 & MCMN & Morrison & Minnesota & intermedius \\
\hline 90876 & MSB-80785 & MCMN & Morrison & Minnesota & intermedius \\
\hline 90943 & MSB-80786 & MCMN & Morrison & Minnesota & intermedius \\
\hline \multicolumn{6}{|c|}{ Museum of Southwestern Biology, University of New Mexico } \\
\hline 56982 & MSB-3826 & SCNM & Sandoval & New Mexico & luteus \\
\hline 56993 & MSB-3827 & SCNM & Sandoval & New Mexico & luteus \\
\hline 56994 & MSB-3828 & SCNM & Sandoval & New Mexico & luteus \\
\hline 56996 & MSB-3829 & SCNM & Sandoval & New Mexico & luteus \\
\hline 56984 & MSB-3830 & SCNM & Sandoval & New Mexico & luteus \\
\hline 56995 & MSB-3831 & SCNM & Sandoval & New Mexico & luteus \\
\hline 56979 & MSB-3832 & SCNM & Sandoval & New Mexico & luteus \\
\hline 56983 & MSB-3833 & SCNM & Sandoval & New Mexico & luteus \\
\hline 56997 & MSB-3834 & SCNM & Sandoval & New Mexico & luteus \\
\hline 56980 & MSB-3835 & SCNM & Sandoval & New Mexico & luteus \\
\hline None & MSB-3836 & SCNM & Sandoval & New Mexico & luteus \\
\hline 56981 & MSB-3837 & SCNM & Sandoval & New Mexico & luteus \\
\hline 56985 & MSB-3838 & SCNM & Sandoval & New Mexico & luteus \\
\hline 56990 & MSB-3839 & SCNM & Sandoval & New Mexico & luteus \\
\hline 56991 & MSB-3840 & SCNM & Sandoval & New Mexico & luteus \\
\hline 56992 & MSB-3841 & SCNM & Sandoval & New Mexico & luteus \\
\hline 56986 & MSB-3842 & SCNM & Sandoval & New Mexico & luteus \\
\hline 56989 & MSB-3843 & SCNM & Sandoval & New Mexico & luteus \\
\hline 56987 & MSB-3844 & SCNM & Sandoval & New Mexico & luteus \\
\hline 56988 & MSB-3845 & SCNM & Sandoval & New Mexico & luteus \\
\hline
\end{tabular}




\section{Appendix B}

\section{Validation of Ramey et al. (2005) control region sequence data}

Ramey et al. (2005) (REA) reported 10 haplotypes shared between and among Zapus hudsonius subspecies. REA used decades-old, dried museum skins as a principal source of genetic material for selected collections used in the phylogeographic comparison. Given the discrepancy between the results of REA and this study (King et al.; KEA) regarding haplotype sharing, we were concerned that this methodological decision may have introduced unnecessary ambiguity to the findings. For example, REA reported the presence of Z.h. preblei haplotypes in DNA extracted from five dried museum skins of $Z$. h. campestris collected from Custer County, SD. The authors suggested this finding indicated recent gene flow and alluded to the presence of these haplotypes as a critical element in the decision to recommend synonymy of these subspecies. KEA sampled 31 Z. h. campestris recently from the same site in Custer County, South Dakota used by REA, along with 30 additional specimens from neighbouring Crook County, Wyoming. All individuals were subjected to mtDNA CR and cyt $b$ sequence analysis. All 61 individuals were determined to posses $Z$. h. campestris-specific mtDNA haplotypes. Moreover, the same conclusion was reached with the microsatellite loci, as no Z. h. campestris individual from either of these collections was assigned to Z. h. preblei. Given the prominent role the haplotypes obtained for the five museum skins from Custer County, South Dakota and two additional specimens from Carter County, Montana have played in the conclusions drawn by REA and the absence of sharing observed in a large sample by this study, we felt compelled to validate the previous findings.

Here we present the results of attempts to validate the mitochondrial DNA control region (CR) sequences reported by REA for seven Z. h. campestris dried museum skin specimens obtained from the Kansas University Natural History Museum (KUNHM) and reported to possess four Z. h. preblei haplotypes. In addition, eight other specimens were obtained to assist in validation of four additional shared haplotypes. An alignment of the $\mathrm{CR}$ sequences for the $15 \mathrm{KUNHM}$ specimens with the sequences generated for the five $Z$. hudsonius subspecies surveyed in this study (KEA) was performed. From this alignment, the identity of the 15 specimens was readily apparent. The follow description and associated table (Table B.1) are provided to assist the reader in assessing the validity of the mtDNA sequences reported by and conclusions made by REA.

\section{Haplotype C/P1}

Eleven specimens were listed by REA as having haplotype C/P1: nine Z. h. preblei (DMNH10405, DMNH10258,
DMNH10270, DMNH10404, DMNH10406, DMNH10407, DMNH9568, PIONEER9568, PIONEER9B89) and two Z.h. campestris (KU109984, KU109985). When the REA GenBank data is compared with this study (KEA), all individuals were found to match the haplotype ZhpCR_A. Tissue samples from two of the specimens (KU109984 and KU109985) were obtained from the KUMNH and sequenced to verify the results of REA. The sequences obtained for the two specimens were not the same as those reported by REA (haplotype $\mathrm{C} / \mathrm{P} 1$ ), both specimens had haplotype ZhcCR_D, a haplotype only observed in Z.h. campestris by KEA.

\section{Haplotype C/P2}

Fourteen specimens were reported by REA to have haplotype C/P2: 12 Z. h. preblei (DMNH9579, DMNH9313, DMNH1315, DMNH10380, DMNH9565, DMNH9563, DMNH9566, DMNH9573, DMNH9572, DMNH9571, DMNH9574, DMNH10607) and two Z.h. campestris (KU109978, KU123592). When the REA GenBank data is compared to that of KEA, all individuals were found to match the haplotype ZhpCR_B. Tissue samples from two of the specimens (KU109978 and KU123592) were obtained from the KUMNH and sequenced. The sequences obtained for the two specimens were not the same as those reported by REA (haplotype C/P2); both specimens had haplotype ZhcCR_D, a haplotype only observed in Z. h. campestris by KEA.

\section{Haplotype C/P3}

Twenty-six specimens were listed as having haplotype C/P3 by REA: 24 Z.h. preblei and two Z.h. campestris (KU110013, KU123597). When the REA GenBank data is compared to that of KEA, all of these individuals were found to match the haplotype ZhpCR_C. Tissue samples from the two Z.h. campestris specimens (KU110013 and KU123597) were obtained from the KUMNH and sequenced. The sequences obtained for the two specimens were not the same as those reported by REA (haplotype C/P3); both specimens had haplotype ZhcCR_D, a haplotype only observed in Z. h. campestris.

\section{Haplotype C/P4}

Ten specimens are listed as having haplotype C/P4 by REA: nine Z. h. preblei and one Z. h. campestris (KU109972). When the REA GenBank data is compared to that of KEA, all of these individuals were found to match the haplotype ZhpCR_D. A tissue sample from the Z.h. campestris specimen (KU109972) was obtained from the KUMNH and sequenced to verify the results of REA. The sequence obtained for the specimen was not the same as that reported by REA (haplotype $\mathrm{C} / \mathrm{P} 4$ ); the specimen had haplotype ZhcCR_A, a haplotype only observed in Z. $h$. campestris. 
Table B1. Results of 15 museum specimens (Kansas University Museum of Natural History; KUMNH) sequenced to verify selected results from Ramey et al. (2005) (REA). Information provided includes: museum catalogue number, collection information, designated subspecies, haplotype reported by REA, corresponding haplotype in King et al. (this manuscript; KEA), the haplotype observed after re-analysis, and the results of an assignment to subspecies based on microsatellite DNA analysis for the seven specimens reported to possess Z. $h$. preblei haplotypes by REA. The number of loci used (in parenthesis) and the ratio of likelihood of assignment to the designated subspecies divided by the score for the REA haplotype designation (i.e. Z. h. preblei) are provided

\begin{tabular}{|c|c|c|c|c|c|c|}
\hline $\begin{array}{l}\text { Catalogue } \\
\text { number }\end{array}$ & $\begin{array}{l}\text { Collection } \\
\text { county, state }\end{array}$ & $\begin{array}{l}\text { Designated } \\
\text { subspecies }\end{array}$ & $\begin{array}{l}\text { REA } \\
\text { haplotype }\end{array}$ & $\begin{array}{l}\text { Corresponding } \\
\text { KEA haplotype }\end{array}$ & $\begin{array}{l}\text { Observed } \\
\text { haplotype§ }\end{array}$ & $\begin{array}{l}\text { Assignment } \\
\text { to subspecies }\end{array}$ \\
\hline KU123597* & Carter County, MT & campestris & $\mathrm{C} / \mathrm{P} 3$ & ZhpCR_C & ZhcCR_D & campestris (8) [1.7] \\
\hline KU123592* & Carter County, MT & campestris & $\mathrm{C} / \mathrm{P} 2$ & ZhpCR_B & ZhcCR_D & campestris (13) [1.7] \\
\hline KU110013* & Custer County, SD & campestris & $\mathrm{C} / \mathrm{P} 3$ & ZhpCR_C & ZhcCR_D & campestris (12) [2.5] \\
\hline KU109984* & Custer County, SD & campestris & $\mathrm{C} / \mathrm{P} 1$ & ZhpCR_A & ZhcCR_D & campestris (11) [2.3] \\
\hline KU109985* & Custer County, SD & campestris & $\mathrm{C} / \mathrm{P} 1$ & ZhpCR_A & ZhcCR_D & campestris (9) [1.1] \\
\hline KU109978* & Custer County, SD & campestris & $\mathrm{C} / \mathrm{P} 2$ & ZhpCR_B & ZhcCR_D & campestris (15) [2.2] \\
\hline KU109972* & Custer County, SD & campestris & $\mathrm{C} / \mathrm{P} 4$ & ZhpCR_D & ZhcCR_A & campestris (9) [2.8] \\
\hline KU112665 & Lawrence County, SD & campestris & $\mathrm{L} / \mathrm{PAL} / \mathrm{C} 1$ & ZhlCR_A & KU45 & \\
\hline KU109963 & Lawrence County, SD & campestris & $\mathrm{L} / \mathrm{PAL} / \mathrm{C} 1$ & ZhlCR_A & ZhcCR_A & \\
\hline KU110033 & Bennett County, SD & pallidus & $\mathrm{L} / \mathrm{PAL} / \mathrm{C} 1$ & ZhlCR_A & NewII & \\
\hline KU112661 & Lawrence County, SD & campestris & $\mathrm{L} / \mathrm{PAL} / \mathrm{C} 2$ & nonet & ZhcCR_D & \\
\hline KU153706 & Leavenworth County, KS & pallidus & $\mathrm{L} / \mathrm{PAL} / \mathrm{C} 2$ & nonet & & \\
\hline KU112663 & Lawrence County, SD & campestris & C9/INT-VII & nonef & ZhcCR_D & \\
\hline KU115730 & Walworth County, SD & intermedius & C9/INT-VII & nonef & ZhcCR_D & \\
\hline KU115700 & Burleigh County, ND & intermedius & C8/10/INT-VI & ZhcCR_D & & \\
\hline
\end{tabular}

MT, Montana; SD, South Dakota; KS, Kansas; ND, North Dakota.

*Z. h. campestris specimens from KUMNH identified by REA as having Z. h. preblei haplotypes.

+Haplotype not observed by King et al. (this study); designated as KU45 by REA in GenBank.

$\ddagger$ Haplotype not observed by King et al.; designated as KU26 by REA in GenBank.

§Thirteen of $15 \mathrm{KUMNH}$ specimens were observed (this study) to have different haplotypes than those reported by REA.

IThis haplotype is unique as it was not observed by either study.

Table B1 presents the results of the comparison among the seven Z. hudsonius campestris specimens. All seven individuals were observed to posses Z.h. campestris haplotypes consistent with the KUMNH identification. In addition to the CR comparison, microsatellite DNA was surveyed in these specimens. Multilocus genotypes of the seven individuals was subjected to a maximum-likelihood assignment test to determine whether the specimen was most closely related to the baseline collections of Z. h. campestris or Z. h. preblei surveyed by KEA following the methods presented in the text. The results of the assignment testing indicated that all seven individuals were on average 2.0 times more likely to be Z. h. campestris than Z. h. preblei.

\section{Haplotype L/PAL/C1}

Haplotype L/PAL/C1 was reported to be shared among three subspecies of $Z$. hudsonius by REA. Eleven specimens were listed as having haplotype L/PAL/C1 by REA: seven Z. h. luteus (MSB58370, MSB56980, MSB56986, MSB56987, MSB56991, MSB56993, MSB62096, and NK856), two Z. $h$. campestris (KU112665, KU109963), and one Z.h. pallidus (KU110033). Of these 11 specimens only one, NK856, has consistent numbering between Appendix 2 of REA and data accessioned in GenBank that allows for direct com- parison. When the REA GenBank data was compared to that of KEA, NK856 was found to match the haplotype ZhlCR_A. Ten other specimens were also found to match this haplotype: six Z.h. luteus (MSB20, MSB21, MSB23, MSB24, MSB25, MSB26, MSB27), two Z. h. campestris (KU25, KU28), one Z. h. pallidus (KU53). Given this evidence, we believe haplotype $\mathrm{L} / \mathrm{PAL} / \mathrm{C} 1$ reported by REA is the same as haplotype ZhlCR_A of KEA. Tissue samples from three of the specimens (KU112665, KU109963 and KU110033) were obtained from KUMNH and sequenced to verify the results of REA. The sequences obtained were not the same as those reported by REA (haplotype L/PAL/C1): specimen KU112665 (Z. h. campestris) had haplotype KU45, specimen KU109963 had haplotype ZhoCR_A and specimen KU110033 was found to have a unique haplotype not previously reported by REA or KEA.

\section{Haplotype L/PAL/C2}

Haplotype L/PAL/C2 was reported to be shared among three subspecies of $Z$. hudsonius by REA. Nine specimens are listed as having haplotype L/PAL/C2 by REA: six Z. h. luteus (MSB86344, MSB91627, MSB91675, NK1584, DMNH8635, and DMNH8633), two Z. h. campestris (KU41451, KU112661), and one Z. h. pallidus (KU153706). Of these nine 
specimens only three (NK1584, DMNH8635, DMNH8633) have consistent numbering between Appendix 2 of REA and data accessioned in GenBank. When the REA GenBank data is compared to that of KEA, NK1584, DMNH8635 and DMNH8633 were not found to match any haplotypes, but did match a haplotype from REA. This haplotype is referred to as KU45; based on a specimen code in GenBank (REA accession) for an individual of Z.h. pallidus with this haplotype. Eight other specimens from GenBank were also found to match this haplotype: six Z. h. luteus (MSB8, MSB7, MSB5, NK1584, DMNH8635, and DMNH8633) and two Z.h. campestris (KU27, KU1). Given this evidence we believe haplotype L/PAL/C2 of REA is identical to haplotype KU45 of the REA GenBank accession. Tissue samples from two specimens (KU153706 and KU112661) were obtained from the KUMNH. Specimen KU153706 was found to have haplotype KU45 as reported by REA. However specimen KU112661 (Z.h. campestris) had haplotype ZhcCR_D, which is not the same haplotype as that reported by REA (haplotype KU45).

\section{Haplotype C9/INT-VII}

Haplotype C9/INT-VII was reported by REA to be shared by Z.h. campestris and Z.h. intermedius. Two specimens were listed by REA as having C9/INT-VII, KU112663 (Z.h. campestris) and KU115730 (Z.h. intermedius). Only KU115730 had consistent numbering between Appendix 2 of REA and data accessioned in GenBank. When the REA GenBank data was compared to that of KEA, KU115730 was not found to match any haplotype. One other REA sequence, KU26 (Z.h. campestris), had the C9/INT-VII haplotype, leading us to believe that KU26 of the GenBank alignment is KU115730. Tissue samples from the two specimens (KU112663 and KU115730) were obtained from the KUMNH. Both specimens, KU112663 and KU115730 were found by KEA to have haplotype ZhcCR_D, not C9/ INT-VII as reported by REA.

\section{Haplotype C5/INT-XIII}

REA report haplotype C5/INT-XIII as being shared between Z. h. campestris and Z.h. intermedius. Specimens KU87040, KU83557, and KU87042 were collected from Harding County, South Dakota and catalogued by the museum as Z. h. campestris. KU115895, KU115896, and KU115897 were collected from the same general location in Harding County, South Dakota but were identified as Z.h. intermedius. The respective collectors of both sets of samples collaborated in a publication (Anderson \& Jone 1971) in which they named all Z. hudsonius from this location as Z.h. campestris. This haplotype is not shared between the two subspecies.

Table B.1 provides the results of the validation for the eight additional museum skins. In total, we investigated eight of 10 haplotypes reported by REA to be shared between or among selected subspecies of Z. hudsonius. Of the 15 specimens analysed, 13 were found to have haplotypes distinctly different from those reported by REA. We believe these findings have identified the presence of a systemic error in the CR data reported by REA. Moreover, the inability to directly link the sequences deposited in GenBank to the specimens listed in Appendix 2 of REA and the associated locality data renders the data useless. Possible reasons for the different sequences reported by REA are contamination, mislabelling of samples, or other procedural incongruity. Given that all the specimens re-evaluated in the current study were found by REA to have haplotypes that were shared among subspecies, the disagreement in DNA sequences reported for these individuals calls into question all of the results of REA based on the mitochondrial DNA genome and prevents analysis of the combined data.

\section{Appendix C}

Microsatellite DNA markers, the total number of alleles observed, and the range of amplified products in the survey of 348 Zapus hudsonius, and associated references

\begin{tabular}{lrrl}
\hline $\begin{array}{l}\text { Microsatellite } \\
\text { locus }\end{array}$ & $\begin{array}{l}\text { Alleles } \\
\text { observed }\end{array}$ & $\begin{array}{l}\text { Size } \\
\text { range }\end{array}$ & Reference \\
\hline Z.7 & 30 & $156-179$ & Ramey et al. (2005) \\
Z.20 & 20 & $103-147$ & Ramey et al. (2005) \\
Z.26 & 16 & $138-174$ & Ramey et al. (2005) \\
Z.48 & 16 & $173-203$ & Ramey et al. (2005) \\
Z.52 & 11 & $154-176$ & Ramey et al. (2005) \\
Ztri2 & 12 & $91-135$ & Vignieri (2003) \\
Ztri17 & 14 & $149-195$ & Vignieri (2003) \\
Ztri19 & 8 & $174-206$ & Vignieri (2003) \\
Ztri24 & 13 & $151-199$ & Vignieri (2003) \\
ZhuC3 & 16 & $204-264$ & King et al. (2006) \\
ZhuC6 & 10 & $100-144$ & King et al. (2006) \\
ZhuC12 & 8 & $96-124$ & King et al. (2006) \\
ZhuC104 & 11 & $222-254$ & King et al. (2006) \\
ZhuC119 & 17 & $207-263$ & King et al. (2006) \\
ZhuC120 & 7 & $145-169$ & King et al. (2006) \\
ZhuC129 & 10 & $200-236$ & King et al. (2006) \\
ZhuC130 & 7 & $258-286$ & King et al. (2006) \\
ZhuD107 & 13 & $213-261$ & King et al. (2006) \\
ZhuD108 & 10 & $138-176$ & King et al. (2006) \\
ZhuD109 & 13 & $133-177$ & King et al. (2006) \\
ZhuD122 & 18 & $201-285$ & King et al. (2006) \\
\hline
\end{tabular}


4358 T. L. KING ET AL.

\section{Appendix D}

Zapus hudsonius mitochondrial DNA control region haplotype (372 base pairs) counts by subspecies and collection

\begin{tabular}{|c|c|c|c|c|c|c|c|c|c|c|c|c|c|c|}
\hline \multirow{3}{*}{$\begin{array}{l}\text { Haplotype } \\
N\end{array}$} & \multicolumn{7}{|c|}{ Z. hudsonius preblei } & \multicolumn{2}{|c|}{ Z.h.intermedius } & \multicolumn{2}{|c|}{ Z.h.campestris } & \multicolumn{2}{|c|}{ Z.h.pallidus } & \multirow{2}{*}{$\frac{\text { Z.h. luteus }}{\text { SCNM }}$} \\
\hline & SOWY & LCCO1 & $\mathrm{LCCO} 2$ & DCCO1 & DCCO2 & ECCO1 & $\mathrm{ECCO} 2$ & BRCSD & MCMN & CCWY & CCSD & BCSD & KBCNE & \\
\hline & 28 & 12 & 16 & 32 & 26 & 19 & 26 & 26 & 21 & 29 & 31 & 16 & 31 & 19 \\
\hline ZhpCR_A & 28 & 12 & 12 & & & & & & & & & & & \\
\hline ZhpCR_B & & & & 6 & 18 & 9 & 11 & & & & & & & \\
\hline ZhpCR_C & & & 4 & 26 & 5 & & & & & & & & & \\
\hline ZhpCR_D & & & & & 3 & 10 & 15 & & & & & & & \\
\hline ZhiCR_A & & & & & & & & 8 & 4 & & & & & \\
\hline ZhiCR_B & & & & & & & & 5 & & & & & & \\
\hline ZhiCR_C & & & & & & & & 13 & & & & & & \\
\hline ZhiCR_D & & & & & & & & & 8 & & & & & \\
\hline ZhiCR_E & & & & & & & & & 3 & & & & & \\
\hline ZhiCR_F & & & & & & & & & 2 & & & & & \\
\hline ZhiCR_G & & & & & & & & & 1 & & & & & \\
\hline ZhiCR_H & & & & & & & & & 2 & & & & & \\
\hline ZhiCR_I & & & & & & & & & 1 & & & & & \\
\hline ZhcCR_A & & & & & & & & & & 25 & 20 & & & \\
\hline ZhcCR_B & & & & & & & & & & 3 & & & & \\
\hline ZhcCR_C & & & & & & & & & & 1 & & & & \\
\hline ZhcCR_D & & & & & & & & & & & 8 & & & \\
\hline ZhcCR_E & & & & & & & & & & & 3 & & & \\
\hline ZhpaCR_A & & & & & & & & & & & & 14 & 10 & \\
\hline ZhpaCR_B & & & & & & & & & & & & 2 & & \\
\hline ZhpaCR_C & & & & & & & & & & & & & 10 & \\
\hline ZhpaCR_D & & & & & & & & & & & & & 7 & \\
\hline ZhpaCR_E & & & & & & & & & & & & & 4 & \\
\hline ZhlCR_A & & & & & & & & & & & & & & 17 \\
\hline ZhlCR_B & & & & & & & & & & & & & & 2 \\
\hline
\end{tabular}


EVOLUTIONARY DISTINCTION OF ZAPUS HUDSONIUS PREBLEI 4359

\section{Appendix E}

Zapus hudsonius mitochondrial DNA cytochrome $b$ region haplotype (1006 base pairs) counts by subspecies and collection.

\begin{tabular}{|c|c|c|c|c|c|c|c|c|c|c|c|c|c|c|}
\hline \multirow{3}{*}{$\begin{array}{l}\text { Haplotype } \\
N\end{array}$} & \multicolumn{7}{|c|}{ Zapus hudsonius preblei } & \multicolumn{2}{|c|}{ Z.h. intermedius } & \multicolumn{2}{|c|}{ Z.h. campestris } & \multicolumn{2}{|c|}{ Z.h.pallidus } & \multirow{3}{*}{$\begin{array}{l}\text { Z.h.luteus } \\
\text { SCNM } \\
19\end{array}$} \\
\hline & SOWY & LCCO1 & $\mathrm{LCCO} 2$ & DCCO1 & $\mathrm{DCCO} 2$ & ECCO1 & ECCO2 & BRCSD & MCMN & CCWY & CCSD & BCSD & KBCNE & \\
\hline & 28 & 14 & 15 & 31 & 14 & 19 & 25 & 26 & 21 & 30 & 30 & 16 & 32 & \\
\hline ZhpCB_A & & 1 & 5 & & & & & & & & & & & \\
\hline ZhpCB_B & & 1 & & & & & & & & & & & & \\
\hline ZhpCB_C & & 1 & & & & & & & & & & & & \\
\hline ZhpCB_D & & 1 & & & & & & & & & & & & \\
\hline ZhpCB_E & & 1 & & & & & & & & & & & & \\
\hline ZhpCB_F & & 9 & 5 & & & & & & & & & & & \\
\hline ZhpCB_G & 9 & & 4 & & & & & & & & & & & \\
\hline ZhpCB_H & & & 1 & & & & & & & & & & & \\
\hline ZhpCB_I & & & & 7 & 11 & 14 & 24 & & & & & & & \\
\hline ZhpCB_J & & & & 23 & & & & & & & & & & \\
\hline ZhpCB_K & & & & 1 & & 1 & & & & & & & & \\
\hline ZhpCB_L & & & & & 2 & & & & & & & & & \\
\hline ZhpCB_M & & & & & 1 & & & & & & & & & \\
\hline ZhpCB_N & & & & & & 1 & & & & & & & & \\
\hline ZhpCB_O & & & & & & 1 & & & & & & & & \\
\hline ZhpCB_P & & & & & & 2 & & & & & & & & \\
\hline ZhpCB_Q & & & & & & & 1 & & & & & & & \\
\hline ZhpCB R & 5 & & & & & & & & & & & & & \\
\hline ZhpCB_S & 1 & & & & & & & & & & & & & \\
\hline ZhpCB_T & 1 & & & & & & & & & & & & & \\
\hline ZhpCB_U & 12 & & & & & & & & & & & & & \\
\hline ZhiCB_A & & & & & & & & & 3 & & & & & \\
\hline ZhiCB_B & & & & & & & & & 1 & & & & & \\
\hline ZhiCB C & & & & & & & & 5 & 4 & & & & & \\
\hline ZhiCB_D & & & & & & & & & 1 & & & & & \\
\hline ZhiCB_E & & & & & & & & & 3 & & & & & \\
\hline ZhiCB_F & & & & & & & & & 1 & & & & & \\
\hline ZhiCB_G & & & & & & & & & 5 & & & & & \\
\hline ZhiCB_H & & & & & & & & & 1 & & & & & \\
\hline ZhiCB_I & & & & & & & & & 2 & & & & & \\
\hline ZhiCB_J & & & & & & & & 13 & & & & & & \\
\hline ZhiCB_K & & & & & & & & 6 & & & & & & \\
\hline ZhiCB_L & & & & & & & & 1 & & & & & & \\
\hline ZhiCB_M & & & & & & & & 1 & & & & & & \\
\hline ZhcCB_A & & & & & & & & & & 1 & & & & \\
\hline ZhcCB_B & & & & & & & & & & 22 & 19 & & & \\
\hline ZhcCB_C & & & & & & & & & & 1 & & & & \\
\hline ZhcCB_D & & & & & & & & & & 1 & & & & \\
\hline ZhcCB_E & & & & & & & & & & 2 & & & & \\
\hline ZhcCB_F & & & & & & & & & & 1 & & & & \\
\hline ZhcCB_G & & & & & & & & & & 1 & & & & \\
\hline ZhcCB_H & & & & & & & & & & & 2 & & & \\
\hline ZhcCB_I & & & & & & & & & & 1 & & & & \\
\hline ZhcCB_J & & & & & & & & & & & 5 & & & \\
\hline ZhcCB_K & & & & & & & & & & & 1 & & & \\
\hline ZhcCB_L & & & & & & & & & & & 2 & & & \\
\hline ZhcCB_M & & & & & & & & & & & 1 & & & \\
\hline ZhpaCB_A & & & & & & & & & & & & 4 & & \\
\hline ZhpaCB B & & & & & & & & & & & & 9 & & \\
\hline ZhpaCB_C & & & & & & & & & & & & 2 & 11 & \\
\hline ZhpaCB_D & & & & & & & & & & & & 1 & & \\
\hline ZhpaCB_E & & & & & & & & & & & & & 10 & \\
\hline ZhpaCB_F & & & & & & & & & & & & & 6 & \\
\hline ZhpaCB_G & & & & & & & & & & & & & 4 & \\
\hline ZhpaCB H & & & & & & & & & & & & & 1 & \\
\hline ZhlCB_A & & & & & & & & & & & & & & 19 \\
\hline
\end{tabular}

